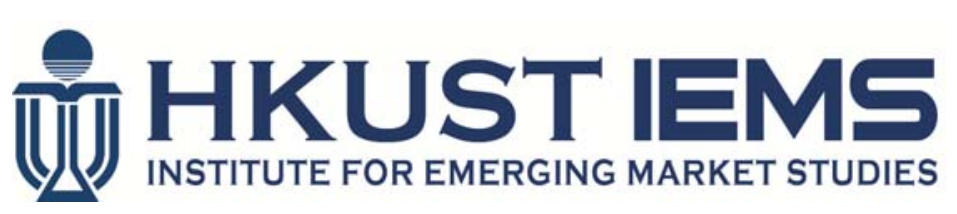

\title{
Credit Distribution and Exports: Microeconomic Evidence from China
}

\author{
Yao Amber LI, Albert PARK, Chen Carol ZHAO
}

HKUST IEMS Working Paper No. 2015-31

November 2015

\begin{abstract}
HKUST IEMS working papers are distributed for discussion and comment purposes. The views expressed in these papers are those of the authors and do not necessarily represent the views of HKUST IEMS.
\end{abstract}

More HKUST IEMS working papers are available at: http://iems.ust.hk/WP 


\title{
Credit Distribution and Exports: Microeconomic Evidence from China
}

Yao Amber LI, Albert PARK, Chen Carol ZHAO

HKUST IEMS Working Paper No. 2015-31

November 2015

\begin{abstract}
This paper explores how the distribution of credit supply within an industry affects that industry's export intensity (the export-to-sales ratio) and export propensity (the ratio of the number of exporters to the total number of firms). Using a heterogeneous firm trade model, we derive two opposing hypotheses: for industries with relatively low (high) foreign market penetration costs, a more dispersed credit distribution decreases (increases) the industry's export intensity and the number of exporters. The empirical results using Chinese firm-level data and bank loan data support both hypotheses and confirm the significant heterogeneous impacts of credit distribution on exports across industries.
\end{abstract}

\section{Authors' contact information}

Yao Amber Li

Department of Economics

Hong Kong University of Science and Technology

E: yaoli@ust.hk

Click here to enter text.

Albert Park

Department of Economics

Hong Kong University of Science and Technology

E: albertpark@ust.hk

\section{Chen Carol Zhao}

Department of Economics

Hong Kong University of Science and Technology

E: zhaochen@ust.hk 


\title{
Credit Distribution and Exports: Microeconomic Evidence from China*
}

\author{
Yao Amber $\mathrm{Li}^{\dagger}$ \\ HKUST
}

\author{
Albert Park ${ }^{\ddagger}$ \\ HKUST, CEPR, and IZA
}

This Version: October 2015

\author{
Chen Carol Zhao ${ }^{\S}$ \\ UIBE
}

\begin{abstract}
This paper explores how the distribution of credit supply among firms within an industry affects that industry's export intensity (the export-to-sales ratio) and export propensity (the ratio of the number of exporters to the total number of firms). Based on a heterogeneous firm trade model, we derive two opposing hypotheses: for industries with relatively low foreign market penetration costs, a more dispersed credit distribution decreases the industry's export intensity and the number of exporters; conversely, for industries with relatively high foreign market penetration costs, the dispersion of credit increases the export intensity and the number of exporters. We test these two hypotheses using Chinese firm-level data and Chinese bank loan data. The empirical results support both hypotheses and confirm the significant heterogeneous impacts of the credit distribution on exports across industries.
\end{abstract}

JEL: F14, G20, L60

Keywords: credit constraints, credit supply, financial development, credit distribution, heterogeneous firms, international trade, liquidity

${ }^{*}$ We are grateful to Robert Staiger, Thomas Chaney, Shang-Jin Wei, Jiandong Ju, Bin Xu, Larry Qiu, Heiwai Tang, Jim MacGee, Edwin Lai, Zhiyuan Li, Yong Wang, Dan Liu, Linke Zhu, the participants of the Asia Pacific Trade Seminars Annual Meeting (Southeast University, Nanjing, June 2013), the CES (Chinese Economists Society) Annual Conference (Southwestern University of Finance and Economics, Chengdu, June 2013), the 2012 Columbia-Tsinghua Conference on International Economics (Tsinghua University, Beijing, October 2012), and the 7th Biennial Conference of Hong Kong Economic Association (Lingnan University, HK, December 2012) for helpful discussions. Yao Amber Li gratefully acknowledges financial support from the Research Grants Council of Hong Kong, China (General Research Funds and Early Career Scheme GRF/ECS Project no. 646112). We also thank Ho Yin Tsoi for excellent research assistance during this project. All errors are our own.

${ }^{\dagger}$ Li: Corresponding author. Department of Economics and Faculty Associate of the Institute for Emerging Market Studies (IEMS), Hong Kong University of Science and Technology, Clear Water Bay, Kowloon, Hong Kong SAR-PRC. Email: yaoli@ust.hk. URL: ihome.ust.hk/ yaoli. Research Affiliate of the China Research and Policy Group at University of Western Ontario.

${ }^{\ddagger}$ Park: Division of Social Science and Department of Economics, Hong Kong University of Science and Technology; Director, HKUST Institute for Emerging Market Studies; Research fellow at Center for Economic Policy Research (CEPR), IZA Institute for the Study of Labor, and International Growth Centre (DFID/Oxford/LSE). Email: albertpark@ust.hk.

§Zhao: University of International Business and Economics. Email: zhaochen@connect.ust.hk. 


\section{Introduction}

A growing body of literature examines the role of credit constraints in international trade. Some studies argue that financially advanced countries have a comparative advantage in financially dependent industries (e.g., Kletzer and Bardhan, 1987; Rajan and Zingales, 1998). Others highlight the aggregate consequences of credit constraints on trade patterns or firm behavior based on a heterogeneous firm framework (e.g., Chaney, 2013; Manova, 2013; Manova, Wei, and Zhang, 2014; Fan, Lai, and Li, 2015).

However, the distributional effects of credit allocation are rarely explored. Given an aggregate credit supply, how can limited credit be allocated more efficiently within an industry to encourage exports? This question is particularly important for developing countries, whose firms usually suffer from a lack of credit support due to their immature financial markets. However, many developing countries are characterized by export-oriented growth. The misallocation of credit may affect export performance and lead to potential efficiency losses (in exports) in those developing countries.

We thus build a heterogeneous firm trade model based on Chaney (2013) to examine the distributional effects of credit allocation on exports. Our model departs from Chaney (2013), as we introduce an intra-industry credit distribution. For simplicity, we assume two representative groups of firms within each industry: one group has access to external credit (i.e., a creditprivileged group), and the other has no access to external financing (i.e., a credit constrained group). The latter group depends only on its own internal cash flows to cover the various costs of exports. Both export intensity (export-to-sales ratio) and export propensity (the fraction of exporting firms) within each sector are targets of this study.

Because the aggregate amount of credit in each industry is constant, a larger amount of credit provided to each supported firm implies narrower coverage of the total number of supported firms within a sector. Similarly, a wider coverage of credit implies a smaller amount of credit for each recipient firm. There is a trade-off between a larger proportion of firms receiving financial support and a larger amount of credit allocated to each supported firm. By holding the aggregate credit supply constant and varying its dispersion within the sector, we can analyze how changes in dispersion affect export performance within the sector. Based on this setup, two hypotheses are provided. For industries with relatively low foreign market penetration costs, a more dispersed credit distribution decreases the export intensity and export propensity. Conversely, for industries with high penetration costs, a more dispersed credit allocation increases export intensity and export propensity.

Empirically, we test two competing hypotheses using Chinese firm-level data and Chinese bank loan data. Due to an underdeveloped financial market, the most productive firms are 
not necessarily guaranteed access to external financing in the current banking system. Thus, China represents an ideal laboratory for testing hypotheses related to financial constraints and exports. Many factors other than productivity may affect firm access to credit in China. For example, external financing access varies greatly in China by regional location and firm ownership.

Thus, we employ several indicators to represent firm access to the credit supply in our tests: (1) the region-level bank loan to GDP ratio (at both the provincial and city levels); ${ }^{1}$ (2) firm ownership (state-owned, private or foreign-invested firms); and (3) the firm-level liability-asset ratio. Indicators (1) and (2) measure external credit constraints, whereas (3) represents an internal credit constraint.

In the tests, we categorize industries into two groups according to their exporting penetration costs. We first use light industry and heavy industry as a simple categorization and in the later discussion we also employ alternative methods of categorizing industries based on their foreign market penetration costs. We test whether the degree of credit dispersion (measured by the variance, percentile ratio, Gini coefficient and Theil index) has different effects on the export intensity and export propensity of these two groups. To address endogeneity issues, we employ the number of banks and the number of employees before the banking system reform as instrumental variables. In various robustness checks, rather than estimating a generalized specification, we test the effects of the credit dispersion for each industry and the correlation of the coefficients with the industry's inherent characteristics. The empirical results support both hypotheses and confirm the heterogeneous distributional impacts of the credit allocation on export intensity and export propensity across industries.

Our paper is closely related to Chaney (2013) and Manova (2013), both of which show that credit constraints perform a significant role in firm exporting behavior through different modeling frameworks. ${ }^{2}$ However, neither of them explores the distribution effects of the credit supply on exports. Our paper takes a further step to answer the following question: Shall we disperse or evenly distribute credit within an industry if the aggregate amount of supply is fixed? Our study delivers a novel message: both the first and second moments of the liquidity supply (i.e., the distribution of the liquidity supply) influence trade. This distribution effect has important implications for developing countries, such as China.

This paper is also related to earlier studies proposing that financial development is a source of comparative advantage in the presence of credit constraints. ${ }^{3}$ Those studies show us the

\footnotetext{
${ }^{1}$ For most firms in China, bank loans are the major source of external financing.

${ }^{2}$ Manova (2013) explores the credit constraint problem through a principal-agent model, which typically categorizes credit supply problems as borrowing-lending activities under asymmetric information. Chaney's (2005) model introduces the liquidity supply as an exogenously determined variable.

${ }^{3}$ See Kletzer and Bardhan (1987), Rajan and Zingales (1998), Beck (2002), and Ju and Wei (2011).
} 
influence of financial development on trade at the aggregate level. In our research, we note that although the level of financial development is considered a source of comparative advantage, given a country's financial development, the way that credit is distributed also significantly affects trade.

This study is also related to previous empirical studies. ${ }^{4}$ Specifically, it is similar to studies that use firm-level data to capture the effects of credit constraints on firm trade behaviors. For example, Minetti and Zhu (2011) explores the effects of credit rationing on exports using survey data of Italian firms; Jarreau and Poncet (2010) uses a Chinese firm-level data to show that credit constraints restrict trade flows; and Hricourt and Poncet (2012) studies the effects of credit constraints on firms' responses to exchange rate changes. However, there are few empirical studies that provide evidence about distributional effects on exports.

The remainder of this paper is organized as follows: Section 2 provides background on the credit supply in China. Section 3 builds a simple model of credit distribution and trade and develops two hypotheses regarding export intensity and export propensity. Section 4 describes the data, measurements, and econometric specifications, and Section 5 presents main empirical results. Section 6 presents the robustness checks, and Section 7 provides further tests of the correlation between the dispersion coefficients and export penetration costs. The final section concludes.

\section{Background Information on China's Credit Supply}

Bank loans are the major source of external financing for firms in China, but other sources are limited. According to the monetary policy executive report released by the Central Bank of China in 2011, approximately $75.2 \%$ of the total credit supply is in the form of bank loans, whereas equity stock, bonds, and other private firm bonds only account for $10.5 \%, 8.8 \%$ and $5.5 \%$ of credit, respectively. Specifically, the majority of bank loans are offered by the "Big Four" state-owned banks in China (accounting for more than $75 \%$ of the total liquidity supply). Although other private and foreign-owned financial institutions are growing rapidly, they supply much less liquidity than the four state-owned Chinese banks. According to the Almanac of Chinas Finance and Banking (2001), small commercial and local banks account for only 19.35\% of total credit supply in China.

Although the aggregate supply of credit has grown rapidly, ${ }^{5}$ liquidity financing is still a

\footnotetext{
${ }^{4}$ For example, Bernard and Jensen (2004), for the US, and Aw and Hwang (1995), for Taiwan and Korea.

${ }^{5}$ According to the "Mapping Global Capital Markets Report (2011)" by McKinsey, the annual growth rate of the credit supply in China reached as high as $17.4 \%$ during the period from 2000 to 2009 and $18.7 \%$ from 2009 to 2010.
} 
constraint for Chinese firms, especially for private firms. The accessibility of credit largely depends on ownership rather than on productivity in China (e.g.,Cull and Xu (2003), Allen, Qian, and Qian, 2005). Private firms are discriminated against in the credit market, especially by state-owned banks (Poncet, Steingress, and Vandenbussche, 2010). State-owned firms typically experience soft budget constraints and are able to obtain large amounts of loans from the banking system (e.g., Bai, Lu, and Tao, 2006; Bailey, Huang, and Yang, 2011). Additionally, foreign firms usually access credit through the international capital market through their parent companies (e.g., Manova, Wei, and Zhang, 2014), and they are thus less constrained than domestic private firms. The impacts of constraints are found to be magnified during financial crises (e.g., Guariglia, Liu, and Song, 2011).

In addition to ownership, other factors, e.g., firm size, collateral availability, location, network with the banks, affect firms' access to bank loans in China. ${ }^{6}$ Specifically, there is a large geographic imbalance in the credit supply across provinces and cities. Table A.3 displays the variation in the average bank loan to GDP ratio across different provinces in China from 2000 to 2007. Firms located in regions that lack bank loans usually suffer from stronger financial constraints than those not located in credit abandonment areas.

Credit shortages become major threats to firms that have no access to normal bank loans. The difference in financing cost between constrained and unconstrained firms is substantial. When private firms cannot obtain bank loans from major banks, they usually turn to private, expensive lenders (e.g., Brandt and Li (2003)). The interest expense of a private loan is usually more than four times that of regular bank loan interest rate from one of the four state-owned banks. ${ }^{7}$

An efficient allocation of credit implies that more productive firms receive more credit, whereas in countries with underdeveloped financial markets, e.g., China, the distribution of credit does not follow that pattern. We use a simple regression to illustrate the weak correlation between firm productivity and bank loan accessibility in China. The results are displayed in Table A.1. In this test, we regress firm labor productivity (measured by the value added per worker) on the bank loan supply (measured by all credit or by long-term bank loans to GDP ratio in the province or city in which the firm is located) and firm liquidity cost, including the $(\log )$ interest expense to assets ratio and $(\log )$ accounts payable to assets ratio. Controlling for ownership and industry type, there is no statistically significant relation between firm productivity and either bank loan supply or liquidity cost.

\footnotetext{
${ }^{6}$ See Chow and Fung (1998), Poncet, Steingress, and Vandenbussche (2010), Li, Meng, Wang, and Zhou (2008) and Allen, Qian, and Qian (2005).

${ }^{7}$ Though these informal loans may not be entirely representative, it is interesting to note that their average interest rate was usually more than $20 \%$, whereas the base rate at year end charged by banks on loans with a maturity of less than six months was $5.35 \%$ in 2010 .
} 


\section{A Simple Model and Hypotheses}

In this section, we incorporate the distribution of the credit supply and firm heterogeneity into a static, partial equilibrium model à la Melitz (2003) and Chaney (2013) and then derive the hypotheses regarding export intensity and export propensity.

\subsection{Model Setup}

There are 2 countries, home and foreign, wherein a continuum of firms produces differentiated goods using only the labor in each of the two countries in $s$ sectors. All foreign variables are denoted by an asterisk. The home country has a population $L$ ( $L^{*}$ for the foreign country). The wages for home and foreign are $w$ and $w^{*}$, respectively. A representative consumer consumes $q_{s}(\omega)$ units of each variety $\omega$ of differentiated goods in sector $s$. Her utility is given by a Cobb-Douglas aggregate $U=\prod_{s} Q_{s}^{\theta_{s}}$ over sector-specific CES consumption indices $Q_{s}=\left[\int_{\omega \in \Omega_{s}} q_{s}(\omega)^{\frac{\sigma-1}{\sigma}} d \omega\right]^{\frac{\sigma}{\sigma-1}}$, where $\Omega_{s}$ is the set of available varieties in the given sector $s, \sigma>1$ is the elasticity of substitution between two varieties of the differentiated goods, $\theta_{s} \in(0,1)$ is the share of each sector of total expenditure $w L$, and $\sum_{s} \theta_{s}=1$. If the ideal price index for sector $s$ is $P_{s}=\left[\int_{\omega \in \Omega_{s}} p_{s}(\omega)^{1-\sigma} d \omega\right]^{\frac{1}{1-\sigma}}$, the representative consumer spends $r_{s}(\omega)=\theta_{s} w L\left(\frac{p_{s}(\omega)}{P_{s}}\right)^{1-\sigma}$ on each variety with a price $p_{s}(\omega)$. The sector index $s$ will be suppressed hereafter, as we will focus on one representative sector in the following analysis.

\subsection{Production and Trade}

Exporting entails a fixed cost and a variable cost. Similar to Chaney (2013), we assume that the cost of entry into the foreign market is denominated in foreign labor. If a firm intends to export, it must pay a fixed cost $w^{*} C_{f}$, which is assumed to be higher than the domestic fixed cost $w C_{d}$. The justification for this assumption is as follows. Typically, firms can literally "split" their production into two production lines: one for the domestic market and the other to serve foreign markets. ${ }^{8}$ The fixed cost for the foreign market production line includes upfront expenditures for foreign production and the costs of marketing in foreign markets. To enter foreign markets, a firm must spend funds on activities, such as developing local distribution networks, customizing products, researching unfamiliar markets, and advertising products. This makes entering foreign markets more difficult than selling in the domestic market because firms are usually more familiar with the domestic market, which in turn, yields higher fixed costs for

\footnotetext{
${ }^{8}$ Even if firms do not separate the production lines for home and foreign markets, we can still obtain similar observation by dividing total fixed costs for production and marketing into two groups of goods: those sold in the domestic market and those exported to foreign markets.
} 
exporting than those for selling in the domestic market. In addition, a firm incurs a variable $\operatorname{cost} \tau>1$ to export, which takes the form of an "iceberg" transportation cost such that $\tau>1$ units of goods must be shipped abroad in order for one unit to arrive in foreign country and the rest melts during transportation.

We assume that each firm draws a random unit labor productivity $x>0$ following a Pareto distribution within a sector. ${ }^{9}$ A firm with productivity $x$ incurs the cost of producing $q_{d}$ units of goods for the home market $c_{d}\left(q_{d}\right)$ as well as the cost of producing $q_{f}$ units of goods for the foreign market $c_{f}\left(q_{f}\right)$ :

$$
\begin{aligned}
c_{d}\left(q_{d}\right) & =q_{d} \frac{w}{x}+w C_{d} \\
c_{f}\left(q_{f}\right) & =q_{f} \frac{\tau w}{x}+w^{*} C_{f}
\end{aligned}
$$

With isoelastic demand functions, the optimal price is a constant markup over the unit cost (including the transportation cost for the foreign market): $p_{d}(x)=\frac{\sigma}{\sigma-1} \frac{w}{x}$ at home and $p_{f}(x)=\frac{\sigma}{\sigma-1} \frac{\tau w}{x}$ abroad. These pricing rules suggest that more productive firms are able to charge lower prices, obtain larger market shares, and in turn, yield higher profits both at home and abroad. Accordingly, a firm with productivity $x$, domestic sales revenue $r_{d}$, and foreign sales revenue $r_{f}$ potentially generates profits $\pi_{d}(x)$ in the home market and $\pi_{f}(x)$ in the foreign market, respectively:

$$
\begin{aligned}
& \pi_{d}(x)=\frac{r_{d}}{\sigma}-w C_{d}=\frac{1}{\sigma} w L\left(\frac{\sigma}{\sigma-1} \frac{w}{x P}\right)^{1-\sigma}-w C_{d} \\
& \pi_{f}(x)=\frac{r_{f}}{\sigma}-w^{*} C_{f}=\frac{1}{\sigma} w^{*} L^{*}\left(\frac{\sigma}{\sigma-1} \frac{\tau w}{x P^{*}}\right)^{1-\sigma}-w^{*} C_{f}
\end{aligned}
$$

In the static model, the underlying assumption is that firms cannot use their profits from past periods to finance their current and future operations. ${ }^{10}$ Therefore, we can implicitly define two productivity thresholds $\bar{x}_{d}$ (as a function of $C_{d}$ ) for survival in the domestic market and $\bar{x}_{f}$ (as a function of $C_{d}^{*}$ ) for profitable entry into the foreign market if we define the function $g(\cdot)$

\footnotetext{
${ }^{9}$ To specify the production distribution, a Pareto distribution is often used in the exisiting literature, for example, Helpman, Melitz, and Yeaple (2004), Melitz and Ottaviano (2008), and Feenstra and Kee (2008), among others.

${ }^{10}$ Because the fixed overhead costs are paid each period, we assume that firms have to distribute profits to shareholders rather than save for future investment at the end of each period.
} 
in the following way: ${ }^{11}$

$$
\begin{aligned}
g(\cdot): \bar{x}_{d} & =\left\{x \mid \pi_{d}(x)=0\right\} \Leftrightarrow \bar{x}_{d}=g\left(C_{d}\right) \\
\bar{x}_{f} & =\left\{x \mid \pi_{f}(x)=0\right\} \Leftrightarrow \bar{x}_{f}=\left(\frac{\tau w}{w^{*}}\right)\left(\frac{C_{f}}{C_{d}^{*}}\right)^{\frac{1}{\sigma-1}} g\left(C_{d}^{*}\right)
\end{aligned}
$$

\subsection{Liquidity Constrained Exporters}

Firms rely on external financing mainly to cover fixed costs. Naturally, exporters often rely more on external liquidity than do non-exporters. The reasons for this pattern have been discussed in previous studies. ${ }^{12}$ For example, most fixed costs for exporting are incurred before export revenues are realized, as exporters typically need a longer time lag to collect the proceeds of sales in foreign markets than they do for sales in the domestic market. Next, we consider only potentially profitable exporters and examine how credit constraints affect their exporting behaviors. In other words, the exporting firms of interest to us are those that can potentially profitably enter foreign markets (i.e., $x>\bar{x}_{f}$ ), but due to a lack of liquidity, they fail to do so.

In the model, liquidity supply $A$ for each firm is exogenously determined in the home country. Because $A$ is the domestic credit supply, it is denominated in units of domestic labor and has a value $w A{ }^{13}$ In reality, a firm's productivity and its external liquidity shock may or may not be correlated, depending on the specific assumptions about the shape of the joint distribution of $(A, x)$. In this paper, we assume that productivity $x$ follows a Pareto distribution and that it is not correlated with external liquidity shock $A$. This assumption fairly describes Chinese firms, as external finance (mainly through bank loans) is often allocated depending on a firm's connections to local banks, ownership and location, rather than depending on firm's productivity. For example, state-owned enterprises (SOEs) have better access to bank loans than do domestic private enterprises (DPEs) even though SOEs are not necessarily more productive than DPEs in many sectors(see Song, Storesletten, and Zilibotti (2011)). In this sense, it is valid to assume that access to finance is not positively associated with profitability.

We further assume that there are two types of external liquidity supplied, a low type $A_{\text {low }}$ and a high type $A_{\text {high }}$. For simplicity, $\theta$ denotes the proportion of existing producers that can obtain only $A_{\text {low }}$. In other words, those firms are liquidity constrained, and the remaining $(1-\theta)$ producers can obtain $A_{H i g h}$.

\footnotetext{
${ }^{11}$ We assume that trade barriers are always sufficiently high, so $\bar{x}_{f}>\bar{x}_{d}$ always holds. This implies that only a subset of firms are able to export and that no firm is able to sell abroad but not domestically.

${ }^{12}$ See Manova, Wei, and Zhang (2014), Chaney (2013), Amiti and Weinstein (2011), and Feenstra, Li, and $\mathrm{Yu}(2014)$.

${ }^{13}$ Here, we implicitly assume that due to the incompleteness of international contracts, foreign investors are not willing to finance domestic exporters.
} 
In this paper, we assume that the exogenous liquidity supply only applies to existing, survivor domestic firms. ${ }^{14}$ To export, an existing firm must have enough liquidity to cover the fixed entry cost $w^{*} C_{f}$. It generates some liquidity from its domestic sales $\pi_{d}(x)$, and it has access to some additional external liquidity $w A_{\text {low }}$ or $w A_{\text {high }}$. Thus, an existing domestic producer is able to export if and only if the following liquidity constraint condition holds:

$$
\begin{aligned}
\pi_{d}\left(x\left(A_{\text {low }}\right)\right)+w A_{\text {low }} & \geq w^{*} C_{f} \text { for the low type } \\
\pi_{d}\left(x\left(A_{\text {high }}\right)\right)+w A_{\text {high }} & \geq w^{*} C_{f} \text { for the high type. }
\end{aligned}
$$

More productive firms generate higher profits in the domestic market and are therefore less dependent on external finance. We can then define a new set of productivity cutoffs for exporting firms below which firms with liquidity $A_{\text {low }}$ (or $A_{\text {high }}$ ) cannot enter the foreign market:

$$
\begin{aligned}
\bar{x}\left(A_{\text {low }}\right) & =\left(1+\frac{w^{*} C_{f}}{w C_{d}}-\frac{A_{\text {low }}}{C_{d}}\right)^{\frac{1}{\sigma-1}} \bar{x}_{d} \\
\bar{x}\left(A_{\text {high }}\right) & =\left(1+\frac{w^{*} C_{f}}{w C_{d}}-\frac{A_{\text {high }}}{C_{d}}\right)^{\frac{1}{\sigma-1}} \bar{x}_{d} .
\end{aligned}
$$

For simplicity, we consider two cases: (1) firms with liquidity supply $A_{\text {high }}$ and (2) extremely liquidity constrained firms with zero external liquidity supply $A_{l o w}=0$. This simplification can naturally be linked to Chinese firms. For example, in the empirical counterpart of the Chinese case, the former can represent SOEs with favorable financial access to bank loans, and the latter describes domestic private firms in extremely credit constrained situations. Access to liquidity is independent of firm productivity. Therefore, we simplify our analysis by assuming two representative groups of firms: one is a group with credit access, and the other is credit constrained. We further assume liquidity supply $A_{\text {high }}$ as multiples of the domestic fixed cost $C_{d}$ and normalize $\frac{A_{h i g h}}{C_{d}}$ to $A$. Then, we derive the productivity cutoff for exporting firms with credit access $\bar{x}(A)$ as well as the cutoff for exporting firms that are credit constrained $\bar{x}(0):{ }^{15}$

$$
\begin{aligned}
\bar{x}(A) & =\left(1+\frac{w^{*} C_{f}}{w C_{d}}-A\right)^{\frac{1}{\sigma-1}} \bar{x}_{d} \\
\bar{x}(0) & =\left(1+\frac{w^{*} C_{f}}{w C_{d}}\right)^{\frac{1}{\sigma-1}} \bar{x}_{d} .
\end{aligned}
$$

\footnotetext{
${ }^{14}$ This assumption implies that firms only face liquidity constraints to access foreign markets.

${ }^{15}$ To focus on potentially profitable exporters, we assume that the condition $\bar{x}_{f} \leq \bar{x}(A)$ holds. This is equivalent to satisfying the following condition: $\left[\frac{w^{*} C_{d}^{*}}{w C_{d}}+\frac{(1-A) C_{d}^{*}}{C_{f}}\right]^{\frac{1}{\sigma-1}} \frac{g\left(C_{d}\right)}{g\left(C_{d}^{*}\right)} \geq \frac{\tau w}{w^{*}}$. This assumption is consistent with a similar condition in Chaney (2013), under which it can be proved that there is a non-empty set of liquidity constrained firms. These firms could profitably export, but they are prevented from doing so by insufficient liquidity.
} 
Let $\phi=1+\frac{w^{*} C_{f}}{w C_{d}}$. We can rewrite the above cutoffs as $\bar{x}(A)=(\phi-A)^{\frac{1}{\sigma-1}} \bar{x}_{d}$ and $\bar{x}(0)=\phi^{\frac{1}{\sigma-1}} \bar{x}_{d}$. From the social efficiency point of view, based on the model, there is no need to allocate credit above $\phi$. However, it is possible that an inefficient allocation of liquidity exists in reality such that $A>\phi$, and this situation is not captured by this simple model. We consider this possibility in a hypothetical case and test its implications in the empirical investigation.

The parameter $\phi$ is key to our analysis because it reflects the degree of difficulty firms face in penetrating a foreign market. We call $\phi$ the "penetration cost" for exporting parameter. A larger value of $\phi$ represents higher barriers to entry into a foreign market. The linkage between the penetration cost, a sunk cost, and the export decision has been studied in previous research, for example, in Dixit (1989) and Roberts and Tybout (1997). In our framework, both productivity cutoffs, $\bar{x}(A)$ and $\bar{x}(0)$, are increasing functions of $\phi$. Therefore, higher penetration costs make entering foreign markets more difficult, regardless of whether the potential profitable exporters can obtain external liquidity supply.

It can be easily seen that $\bar{x}(A)<\bar{x}(0)$, which indicates that credit-privileged firms have advantages in exporting because it is easier for them to surpass the productivity threshold to become exporters. Additionally, differentiating (3) with respect to $A$ shows that $\frac{\partial \bar{x}(A)}{\partial A}<0$. In other words, the liquidity supply and productivity can be substitutes in exporting. Specifically, a low-productivity firm could export if it obtained a sufficient amount of external liquidity support, but a liquidity constrained producer could also export if it were sufficiently productive.

\subsection{Productivity of Exporters and Non-exporters}

As the liquidity supply impacts selection into exporting, it also affects the average productivity of exporters and non-exporters. We use $X_{f}$ to denote the average productivity of exporters in industry $s$ and $X_{d}$ to denote the average productivity of non-exporters. The former is calculated as the arithmetic mean of the productivity of firms above the exporting cutoffs $\bar{x}(A)$ for firms with liquidity and $\bar{x}(0)$ for firms without liquidity. Similarly, the latter is computed as the arithmetic mean of productivity for those firms below the exporting cutoffs. We assume that the equilibrium distribution of productivity for incumbent firms follows a Pareto distribution: $x \sim \operatorname{Pareto}\left(\bar{x}_{d}, \alpha\right),{ }^{16}$ with c.d.f. $F(x)=1-\left(\frac{\bar{x}_{d}}{x}\right)^{\alpha}$.

In equilibrium, depending on the accessibility of the external credit supply, the distribution of productivity for successful exporters is given by $\frac{f(x)}{1-F(\bar{x}(A))}$ if they enjoy access to external credit and $\frac{f(x)}{1-F(\bar{x}(0))}$ if they could not obtain external credit, where $f(x)$ is the corresponding

\footnotetext{
${ }^{16}$ For convenience, we denote the minimum productivity by $\bar{x}_{d}$, which is the survival cutoff for domestic firms in equilibrium. We acknowledge that $\bar{x}_{d}$ could be influenced by liquidity supply $A$. However, considering this change will not alter our main predictions on exports. For simplicity, we treat this lower bound of productivity as constant in our analysis.
} 
probability density function. Likewise, the distribution of productivity for non-exporters is given by $\frac{f(x)}{F(\bar{x}(A))}$ and $\frac{f(x)}{F(\bar{x}(0))}$ for non-constrained and constrained firms, respectively. We then define the average productivity for exporters $X_{f}$ and the average productivity for non-exporters $X_{d}$ as follows:

$$
\begin{aligned}
X_{f} & =(1-\theta) \int_{\bar{x}(A)}^{\infty} \frac{x}{1-F(\bar{x}(A))} d F(x)+\theta \int_{\bar{x}(0)}^{\infty} \frac{x}{1-F(\bar{x}(0))} d F(x) \\
X_{d} & =(1-\theta) \int_{\bar{x}_{d}}^{\bar{x}(A)} \frac{x}{F(\bar{x}(A))} d F(x)+\theta \int_{\bar{x}_{d}}^{\bar{x}(0)} \frac{x}{F(\bar{x}(0))} d F(x) .
\end{aligned}
$$

Given the properties of the Pareto distribution, we can simplify equations (5) and (6) into the following expressions (see the Appendix for the derivation):

$$
\begin{aligned}
& X_{f}=\frac{\alpha}{\alpha-1}[(1-\theta) \bar{x}(A)+\theta \bar{x}(0)] \\
& X_{d}=\frac{\alpha}{\alpha-1}\left[(1-\theta)\left(\frac{\bar{x}(A)^{\alpha} \bar{x}_{d}-\bar{x}_{d}^{\alpha} \bar{x}(A)}{\bar{x}(A)^{\alpha}-\bar{x}_{d}^{\alpha}}\right)+\theta\left(\frac{\bar{x}(0)^{\alpha} \bar{x}_{d}-\bar{x}_{d}^{\alpha} \bar{x}(0)}{\bar{x}(0)^{\alpha}-\bar{x}_{d}^{\alpha}}\right)\right] .
\end{aligned}
$$

Equation (7) together with the property that $\frac{\partial \bar{x}(A)}{\partial A}<0$ yields $\frac{\partial X_{f}}{\partial A}<0$, which implies that the average productivity level for exporters decreases as the liquidity supply $A$ increases. This proposition is consistent with the intuition that a greater liquidity supply reduces the productivity threshold for exporting firms and encourages more low-productivity firms to select into exporting. This pattern in turn reduces the average productivity of exporters in the industry. This proposition further confirms the substitution effect between productivity and credit and is in line with the recent literature on credit constraints and trade (see, e.g., Manova, 2013 and Chaney, 2013).

\subsection{Revenue for Exporters and Non-exporters}

In addition to facilitating firm selection into exporting, credit supply can also impact the sales revenues of exporters and non-exporters. Combining the price index and the revenue function in section 3.1 with equations (1) and (2) yields the total sales revenue in the foreign market $r_{f}(x)$ and the revenue in the domestic market $r_{d}(x)$ :

$$
\begin{aligned}
& r_{f}(x)=\kappa_{1} x^{\sigma-1}, \text { where } \kappa_{1}=\sigma w^{*} C_{f}\left(\frac{w^{*}}{\tau w} \frac{1}{\bar{x}_{d}^{*}}\right)^{\sigma-1} \\
& r_{d}(x)=\kappa_{2} x^{\sigma-1}, \text { where } \kappa_{2}=\sigma w C_{d}\left(\frac{1}{\bar{x}_{d}}\right)^{\sigma-1}
\end{aligned}
$$

Using the property of Pareto distribution that if $x \sim \operatorname{Pareto}\left(\bar{x}_{d}, \alpha\right)$, then $x^{\sigma-1} \sim \operatorname{Pareto}\left(\bar{x}_{d}^{\sigma-1}, \frac{\alpha}{\sigma-1}\right)$, 
the firm revenues also follow the Pareto distribution. ${ }^{17}$ Consequently, the distribution function of successful exporters becomes the following: $\frac{f(x)}{1-F(\bar{x}(A))}$ or $\frac{f(x)}{1-F(\bar{x}(0))}$, where $F(x)=1-\left(\frac{\bar{x}_{d}}{x}\right)^{\alpha}$. For non-exporters, it follows a distribution of $\frac{f(x)}{F(\bar{x}(A))}$ or $\frac{f(x)}{F(\bar{x}(0))}$.

Following a similar approach as for the productivity calculation, we obtain the average revenues for both exporters $\left(R_{f}\right)$ and non-exporters $\left(R_{d}\right)$ (see the Appendix for the detailed calculations):

$$
\begin{gathered}
R_{f}=\frac{\alpha \kappa_{1}}{1+\alpha-\sigma}\left[(1-\theta) \bar{x}(A)^{\sigma-1}+\theta \bar{x}(0)^{\sigma-1}\right] \\
R_{d}=(1-\theta)\left(\frac{\alpha \kappa_{2}}{1+\alpha-\sigma}\right)\left[\frac{\bar{x}(A)^{\alpha} \bar{x}_{d}^{\sigma-1}-\bar{x}_{d}^{\alpha} \bar{x}(A)^{\sigma-1}}{\bar{x}(A)^{\alpha}-\bar{x}_{d}^{\alpha}}\right]+\theta\left(\frac{\alpha \kappa_{2}}{1+\alpha-\sigma}\right)\left[\frac{\bar{x}(0)^{\alpha} \bar{x}_{d}^{\sigma-1}-\bar{x}_{d}^{\alpha} \bar{x}(0)^{\sigma-1}}{\bar{x}(0)^{\alpha}-\bar{x}_{d}^{\alpha}}\right] .
\end{gathered}
$$

We can then notice that the average revenue for exporters decreases as high type liquidity supply A increases, that is, $\frac{\partial R_{f}}{\partial A}<0$. Keeping the proportion of financially supported firms unchanged,(i.e., $\theta$ is unchanged), increasing A leads increasingly less productive firms to enter the foreign market, which pushes down the average sales revenue level.

\subsection{Export Propensity and Export Intensity}

We use $\mu$ to denote the mean of the external credit supply in an industry and $\sigma^{2}$ for the variance of the external credit supply in an industry. It is straightforward to find a mapping between $\left(\mu, \sigma^{2}\right)$ and original pair $(A, \theta)$.

$$
\begin{gathered}
\mu=(1-\theta) A, \sigma^{2}=\theta(1-\theta) A^{2} \\
A=\frac{\mu^{2}+\sigma^{2}}{\mu}, \theta=\frac{\sigma^{2}}{\mu^{2}+\sigma^{2}} .
\end{gathered}
$$

By substituting $(A, \theta)$ with $\left(\mu, \sigma^{2}\right)$ we can determine the influence of the liquidity supply distribution, i.e., $\sigma^{2}$ on exporting, such as export revenue $R_{f}$ and the number of exporters $N_{f}$.

For example, if we use $N$ to denote the total number of firms in the home country, the total number of exporters within the sector $N_{f}$ (i.e., export propensity ) becomes:

$$
N[(1-\theta) P(x>\bar{x}(A))+\theta P(x>\bar{x}(0))]=N \bar{x}_{d}^{\alpha}\left[(1-\theta) \bar{x}(A)^{-\alpha}+\theta \bar{x}(0)^{-\alpha}\right] .
$$

Let's denote the average revenue for exporters as $R_{f}$ and the average revenue for the whole domestic producers (including both exporters and non-exporters) as $\bar{R}$, where $\bar{R}=$

\footnotetext{
${ }^{17}$ Many previous studies, such as di Giovanni and Levchenko (2009) and Axtell and Florida (2001), verify that actual firm size indeed follows a similar Pareto distribution.
} 
$\int_{\bar{x}_{d}}^{\infty} r(x) d F(x)=\frac{\alpha \cdot \kappa_{2}}{1+\alpha-\sigma}{\overline{x_{d}}}^{\sigma-1}$. Exporter intensity $\pi^{f}$, defined as the export revenues to total sales within an industry, i.e., $\pi^{f}=\frac{R_{f} N_{f}}{\bar{R} N}$ satisfies the following equation.

$$
\begin{aligned}
\pi^{f} & =\frac{\kappa_{1}}{\kappa_{2}} \frac{\left[(1-\theta) \bar{x}(A)^{\sigma-1}+\theta \bar{x}(0)^{\sigma-1}\right]}{\bar{x}_{d}^{\sigma-1}} \bar{x}_{d}^{\alpha}\left[(1-\theta) \bar{x}(A)^{-\alpha}+\theta \bar{x}(0)^{-\alpha}\right] \\
& =\frac{\kappa_{1}}{\kappa_{2}}[(1-\theta)(\phi-A)+\theta \phi]\left[(1-\theta)(\phi-A)^{\frac{-\alpha}{\sigma-1}}+\theta \phi^{\frac{-\alpha}{\sigma-1}}\right]
\end{aligned}
$$

By using the mapping between $(A, \theta)$ and $\left(\mu, \sigma^{2}\right)$ in equation $(13)$, we can derive export propensity $N_{f}$ and export intensity $\pi^{f}$ as function of $\left(\mu, \sigma^{2}\right)$. Then, differentiating $\pi^{f}, N_{f}$ with respect to $\sigma^{2}$, we obtain the following proposition: If the penetration cost satisfies $\mu<$ $\phi<\frac{\sigma^{2}+\mu^{2}}{\mu}\left(\frac{\alpha}{\sigma-1}+1\right)$, then the number of exporters increases as the credit supply becomes more dispersed, (i.e., as $\sigma^{2}$ increases). Conversely, for industries with low penetration costs or excess credit (i.e., when $\phi<\mu$ ), we hypothesize that the number of exporters decreases as the credit supply becomes more dispersed. Therefore, we formalize the following testable hypothesis regarding the export propensity.

Hypothesis 1. If the penetration cost is sufficiently high (i.e., $\mu<\phi<\frac{\sigma^{2}+\mu^{2}}{\mu}\left(\frac{\alpha}{\sigma-1}+1\right)$ ), then the number of exporters and, therefore, the export propensity increases as the credit supply becomes more dispersed. If the penetration cost is relatively low, then the export propensity increases as the credit supply becomes more evenly distributed.

The intuition behind this hypothesis is that if export entry costs are sufficiently sizable, exporters require more credit to enter a foreign market. Thus, then deepening of liquidity supply may stimulate exports. If the entry cost is not sizable, then for a given aggregate credit supply, an increase in the liquidity supply for each firm within the credit-privileged group reduces the total number of firms receiving support. A reduction in the number of firms receiving external financing is associated with a decrease in the number of exporters. ${ }^{18}$

Similarly, we derive another proposition that associate export intensity $\pi^{f}$ defined as the export-to-sales ratio with the dispersion of the liquidity supply $\sigma^{2}$ : If the entry cost is sufficiently large, (i.e., if $\mu<\phi<\frac{\sigma^{2}+\mu^{2}}{\mu}\left(\frac{\alpha}{\sigma-1}+1\right)$ ), then the export intensity increases as the credit supply becomes more dispersed. Conversely, for the hypothesized cases for sectors with sufficiently low entry costs (i.e., $\phi<\mu$ ), then the export intensity increases as the credit supply becomes more evenly distributed. Therefore, we form the following testable hypothesis regarding export intensity.

Hypothesis 2. If the entry cost is sufficiently large (i.e., $\mu<\phi<\frac{\sigma^{2}+\mu^{2}}{\mu}\left(\frac{\alpha}{\sigma-1}+1\right)$ ), then the

\footnotetext{
${ }^{18}$ However, the effect of increasing $\mathrm{A}$ on aggregate exporter revenue is ambiguous for an industry (see the Appendix).
} 
export intensity increases as the credit supply becomes more dispersed, but if the penetration cost is relatively low, then the export intensity increases as the credit supply becomes more evenly distributed.

The intuition behind this hypothesis follows that the export penetration cost $\phi$ matters for the relationship between export intensity $\pi^{f}$ and credit supply dispersion $\sigma^{2}$. Provided that the fixed cost of entry is not very high, there is a large number of potential exporters could successfully enter as long as they can obtain access to credit. In this way, a more evenly distributed liquidity supply may be favorable for exports. Conversely, if the fixed cost is high, which implies high barriers to entry into foreign markets, only those firms that are sufficiently profitable can survive abroad. It is more efficient to finance among only a few potential exporters. In other words, for firms that are not productive enough to export, it would be an inefficient way to waste limited liquidity. Because these firms remain to fail even if offered a considerable amount but still inadequate financial support.

\section{Data and Measurements}

\subsection{Data Source}

In the empirical section, we test our hypotheses using two data sources: the firm-level survey of Chinese Industrial Enterprises (CIE) and bank loans as recoded in the Almanac of China's Finance and Banking. The sample period ranges from 2001 to 2007. The CIE database records detailed information for Chinese manufacturing firms covering 31 provinces, including provinceequivalent municipal cities whose annual revenues exceed 5,000,000 RMB. The data have been cleaned following Guariglia, Liu, and Song (2011). We excluded observations with negative sales, as well as negative total assets minus total fixed assets. We also excluded firms whose fixed assets minus accumulated depreciation are negative. Our sample is an unbalanced panel, with a total number of observations ranging from a minimum of 271,484 to a maximum of 336,768 .

We categorize those firms to different groups according to their ownership and the fraction of capital paid in by investors: state-owned firms, foreign-invested firms (including investment from Hong Kong, Macao and Taiwan) and private firms (including investment from legal entities and individuals and collective investment). SOEs include both wholly state-owned firms and partial state holdings, where the latter are firms with over $50 \%$ share of state holdings. Table A.2 (see Appendix) records the proportion of each category in our sample. The SOE share declined from 27.64 in 2001 to 5.42 in 2007. However, domestic private firms increased from 
54.9 to 74.42 during the sample period. The number of foreign-invested firms increased from 6.14 to 11.35, and the number of joint ventures (JVs) declined from 11.32 to 8.81 .

The other data that we use in this test are bank loan statistics that cover 31 provinces and province-equivalent municipal cities. The bank loan statistics are extracted from the Almanac of China's Finance and Banking, which covers all bank loan information (short-term loans, long -term loans and all credit) from 2001 to 2007. Table A.3 presents the bank loan ratios: one ratio is for all credit (including short-term and long-term credit) to GDP ratio, whereas the other accounts for only long-term loans. The ratio is an average value over years, and it shows unbalanced bank loan access depending on geographic location, e.g., at both the province and city levels. In Table A.3, the all credit to GDP ratio ranges from 0.66 (Hunan) to 2.29 (Beijing). Based on these statistics, we find that province-equivalent municipal cities, Beijing, Shanghai, and special economic zone Shenzhen, usually enjoy more adequate credit supplies than other areas. (The bank loan to GDP ratio is very high in Beijing, greater than in any other province.) Due to strategic development planning (development campaigns), the western regions and first-tier major cities (such as Beijing and Shanghai) actually exhibit larger ratios than their counterparts in the eastern regions and in low-tier cities.

\subsection{Measures}

Two measures are used to proxy for export performance at the sector level: the export intensity and the ratio of exporters. The industry export intensity is the ratio of the aggregate exports to the total sales of each industry. The ratio of exporters is the exporter share in each industry. The sector (industry) is defined at 4-digit level according to the CIC (China Industry Classification).

We employ several indicators of firm access to credit from both external and internal sources. To proxy for firms' external finance access, we trace the regionally based bank loan supply. First, according to the province/city in which the firm is located, we gather regional-level total bank loans as the external credit supply for the firm. Second, we use the firm's ownership to indicate the difficulty of obtaining external credit. Following Jarreau and Poncet (2010), Manova (2013) and Guariglia, Liu, and Song (2011), we assign both SOEs and foreign-invested firms to the credit-privileged group, and private firms are assigned to the credit constrained group. To proxy for internal financing constraints, we use the firm's liability ratio, especially the long-term liability ratio, to reflect the firm's internal financial status and credit access. ${ }^{19}$

The distribution of credit access is measured by the following indices: standard deviation, percentile ratio, Theil index and Gini coefficient. All of these indices are computed at the 4-

\footnotetext{
${ }^{19}$ The liability ratio is the liability amount relative to total assets, as in Egger and Kesina (2010), the main indicator of the accessibility of external financing among Chinese firms.
} 
digit industry level. The percentile ratio is calculated between top 90th percentile and the 10th percentile $^{20}$ The Gini coefficient and Theil index are used to measure the degree of inequality in the credit allocation. The calculation of these two indices is provided in Appendix.

Based on the bank loan supply and firm liability information for the sample, we provide summary statistics for the credit distribution of each sector, including the standard deviation, percentile ratio, Gini coefficient and Theil index ${ }^{21}$ in Table A.4. For example, standard deviation ranges from 0.18 to 0.40 , and the percentile ratio ranges from 1.63 to 2.49 across industries. The standard deviation, percentile ratio, Gini and Theil indices are highly correlated with each other. The four credit distribution indices serve as proxies for each other.

\section{$5 \quad$ Empirical Results}

\subsection{Categorizing Industries}

The hypotheses suggest two patterns of credit allocation depending on an industry's penetration costs of exporting. We employ a simple method to categorize all industries into light/heavy categories according to the label offered by National Bureau of Statistics of China. The industry label offers a natural way to group industries according to their barriers to entry. Later, we will use an alternative method of categorizing industries based on their foreign market penetration costs and re-examine our main results.

Heavy industries are defined as those that typically involve high capital costs (i.e., they are capital intensive), high barriers to entry and low transportability. In our data set, heavy industries industries include the chemical and plastics, steel and oil refining and production, mining, industrial machinery and mass transit industries. Heavy industries typically require more advanced resources and facilities, and the items produced by heavy industries are typically equipment and intermediate crude materials, such as iron, coal, oil, and ships. On the contrary, light industries are usually less capital intensive than heavy industries, and they are more consumer oriented. Additionally, most light industry products are for consumption rather than intermediate inputs used in further processing.

To justify this method of categorizing industries, we use a probit model to illustrate the relationship between a heavy/light dummy variable and export penetration costs. We code heavy industries as 1 and light industries as 0 and then regress the industry type (at the 4digit SIC level) on the export intensity and the exporter ratio. The results show that heavy

\footnotetext{
${ }^{20}$ Similar measurements are used in Balasubramanian and Sivadasan (2009) and Herrera and Minetti (2007) to capture dispersion.

${ }^{21}$ The index values displayed are computed at the 2-digit industry level.
} 
industries are more likely have smaller exporter ratios and export intensities. They also show that heavy industries are associated with higher barriers to entry but that light industries are easier to export.

\begin{tabular}{l||l|l}
\hline \hline Probit & Export Intensity & Exporter Share \\
\hline Industry type (Heavy industry $=1)$ & $-1.732^{* * *}$ & $-0.358^{* * *}$ \\
\hline \hline
\end{tabular}

\subsection{Export Intensity Tests}

In the baseline specification, the dependent variable expint ${ }_{s t}$ is export intensity (the value of exports to total sales) for industry $s$ at time $t$. disp $p_{s t}$ denotes the credit distribution index within industry $s$ at time $t$. The industry dummy IND indicates the category of industry, which equals one if $s$ is a heavy industry and zero if a light industry. $X_{t}$ is a vector of industrylevel characteristic controls:

$$
\operatorname{expint}_{s t}=\beta_{1} \operatorname{disp}_{s t}+\beta_{2} \operatorname{disp}_{s t} \times I N D_{s t}+\beta_{3} I N D_{s t}+\beta_{4} X_{s t}+c_{t}+\epsilon_{s t} .
$$

For $X_{s t}$, we include the value added per person ( $V A D$ per worker), the total number of firm (FIRMNO), the capital to labor ratio and the industry average credit accessibility AverageCredit as industry-level controls. $V A D$ per worker represents the average productivity, Capital Labor Ratio measures the capital intensity of each industry s, and FIRMNO reflects the competitiveness of each industry. The industry's average credit accessibility corresponds to the share of credit-privileged firms (SOEs and multinational firms), the average bank loan ratio and the liability ratio within each industry. In our regression, we include a province dummy and year fixed effects.

According to the hypotheses, for industries with low fixed entry costs, increased dispersion reduces industry export intensity, which implies a negative $\beta_{1}$, but for those industries with high fixed costs, this negative relationship is mitigated or even replaced by a positive relationship, which implies a positive $\beta_{2}$. 


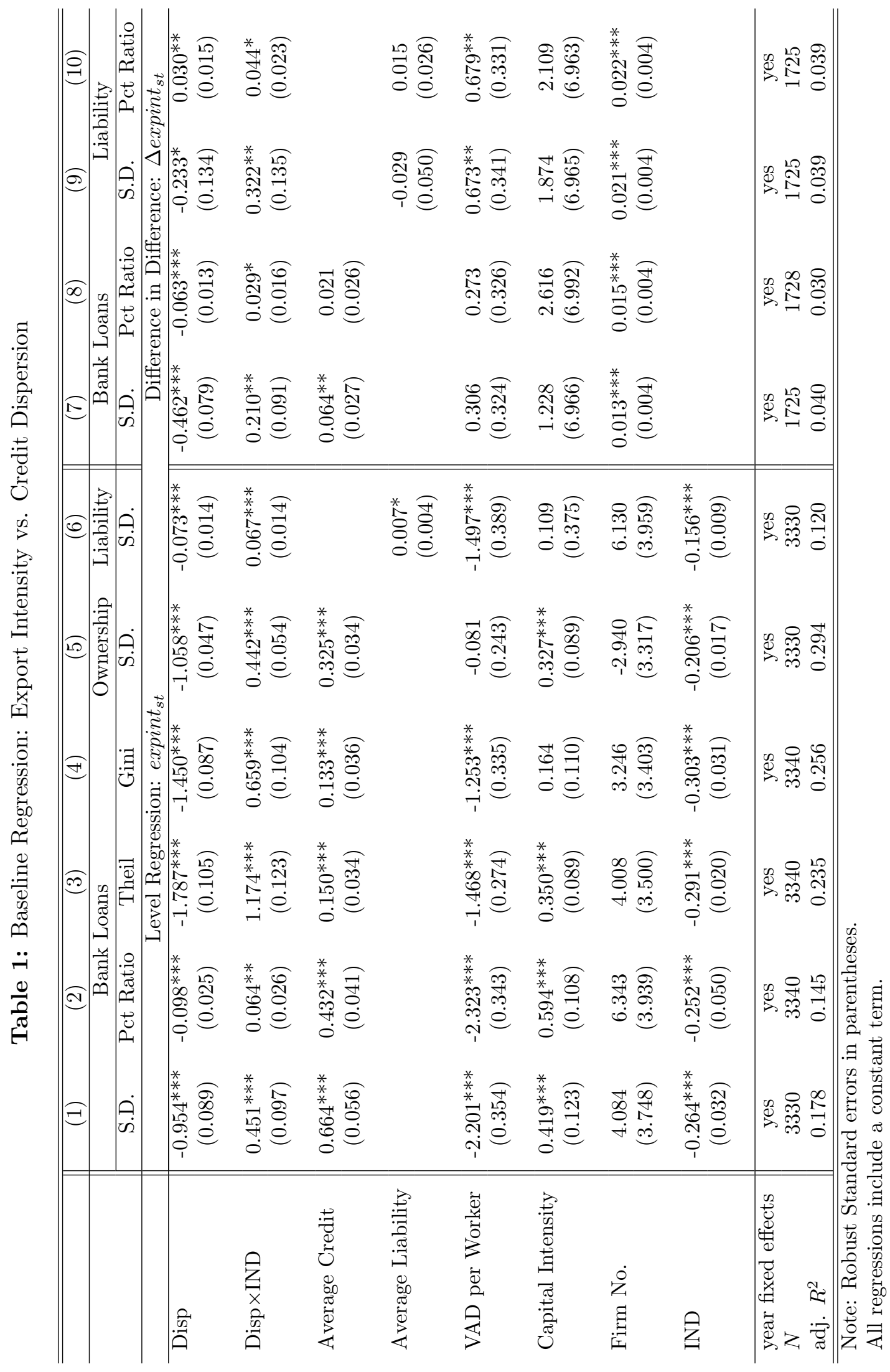


In Table 1, the first four columns employ bank loan information to compute dispersion, including the standard deviation, percentile ratio, and Theil and Gini indices; column 5 uses firm ownership; and column 6 is based on liabilities.

For all of the dispersion measurements $d i s p_{s t}$, export intensity is negatively related to the credit dispersion variables. The interaction between dispersion by industry type, disp $p_{s t} \times I N D$, is negative. Based on these results, credit dispersion exerts a negative effect on export intensity for industries with low export penetration costs. This effect would be mitigated for industries with high export penetration costs. For those industries with large entry barriers, an increase in dispersion encourages export intensity.

For the control variables in the vector $X_{\text {st }}$, an average industry credit supply (Average Credit) has a positive effect on exports. This result suggests the exports increase with the aggregate liquidity supply of each industry. Productivity $(V A D)$ plays a insignificant role in exporting. Competitiveness (FIRMNO) within the industry plays a negligible role in exporting.

In addition, we use a first-order difference regression as an alternative test to alleviate concerns about unobservable industry-level characteristics. The dependent $\left(\Delta\right.$ expint $\left._{s t}\right)$ and independent $\left(\Delta D i s p_{s t}, \Delta D i s p_{s t} \times I N D, \Delta\right.$ AverageCredit, and so on $)$ variables are the firstorder differences between year $t$ and year $t-1$. In columns $7-10$ of Table 1 , the results are reported based on bank loans and firm liabilities. Both standard deviation and percentile ratio are used as credit distribution measures for each industry. The bank loan results show a similar pattern to the baseline regression, and the liability ratio is less robust than previous specifications.

\subsection{Export Propensity Tests}

We also consider the effects of the credit distribution on the export propensity (the exporters ratio) within industry $s$. Compared with the previous test, the only difference is that the dependent variable is the export propensity expropst rather than the export intensity. The specification is as follows:

$$
\operatorname{exprop}_{s t}=\beta_{1} \operatorname{disp}_{1 t-1}+\beta_{2} d i s p_{1 t-1} \times I N D_{s t}+\beta_{3} X_{s t}+\beta_{4} I N D_{s t-1}+c_{t}+\epsilon_{s t} .
$$

In Table 2, credit dispersion disp $p_{s t}$ exerts a similar effect on the export propensity. As

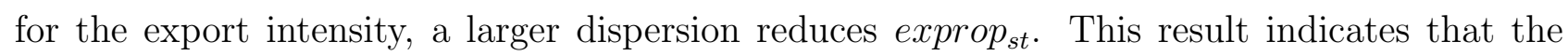
number of exporters in the sector increases as the credit supply is distributed more evenly. A second interaction term, Disp $\times I N D$, shows a significant, positive sign, which indicates that a dispersed credit allocation encourage firms to export in the heavy industries. 


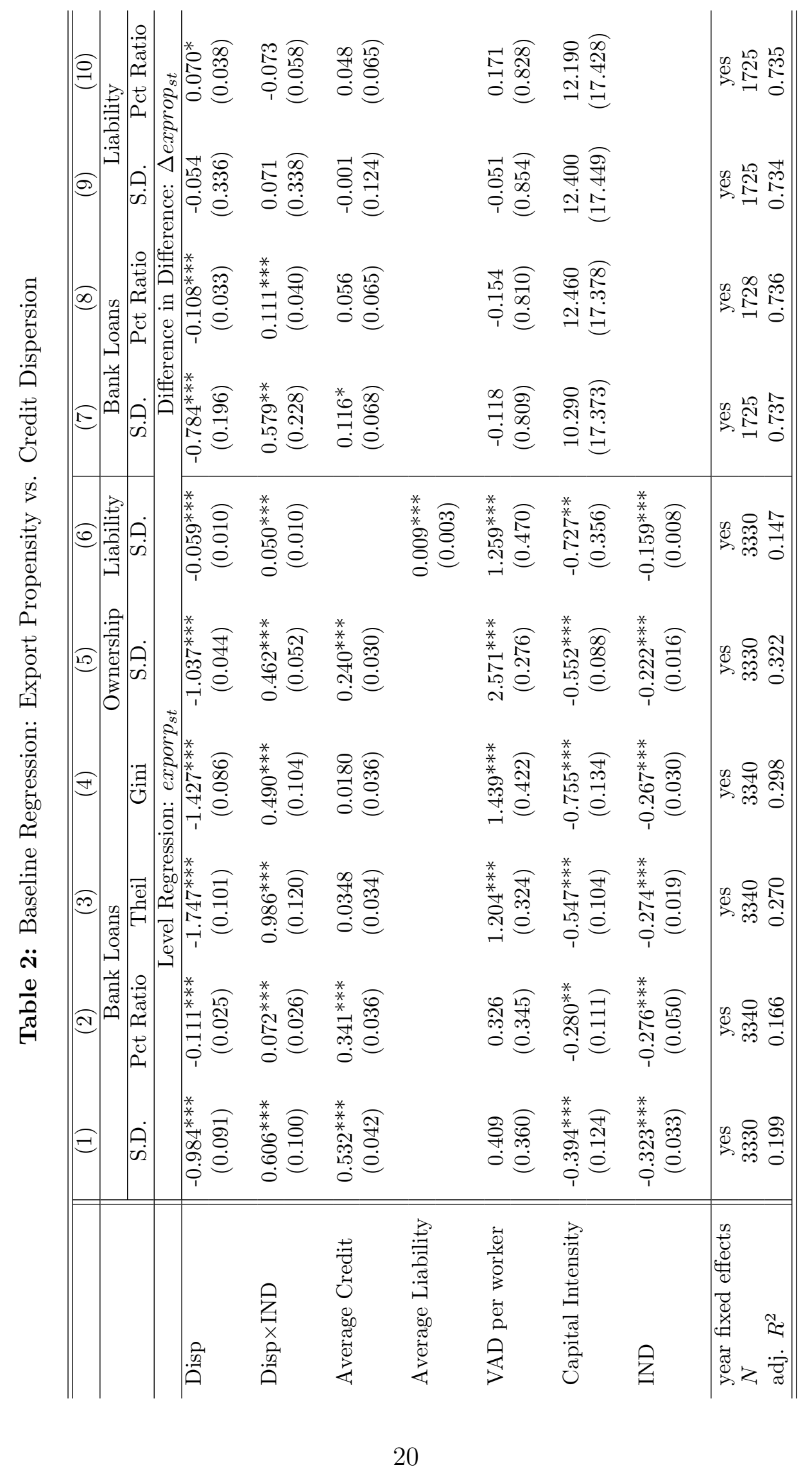


Additionally, the industry dummy $(I N D)$ has a significantly negative sign, which suggests that the percentage of exporters within heavy industries is smaller than that within light industries.

We also conduct a first-order difference test to eliminate the effects of unobservable industry characteristics. Columns $7-10$ of Table 2 display the effects of the credit distribution on the export propensity. The pattern is similar to the baseline results using bank loans to measure the credit supply. However, for liability measurements, especially when using the percentile ratio, this pattern is weaker.

\subsection{Potential Endogeneity and Instrumental Variable Estimation}

There is a concern of reverse causality in previous baseline results. For example, exporting firms are more likely to be profitable than non-exporting firm, and exporting signals higher efficiency to creditors. Thus, the concern is that the external liquidity supply responds to characteristics that are linked to a firm's efficiency. To address these potential endogeneity issues, we employ an instrumental variable approach to verify our predictions in this section. We use the initial bank loan allocation before the reform of the Chinese banking system as an instrumental variable.

\subsubsection{Instrumental Variable for the Credit Supply}

Prior to 2000, the financial market in China was very inefficient and was characterized by insufficient bank loans and bank branches as well as considerable bad debt on banks' books. During the early 2000s, China launched a nation-wide reform of the banking system. After this reform, both the number of bank employees and the number of bank branches (including both state-owned and non-state-owned banks) improved dramatically.

Although a large of number of banks appeared and the aggregate liquidity supply increased over the 2001-2007 period, the geographical distribution of the credit supply in China shifted little. Imbalances in the credit supply still exist across cities due to uneven development. More banks are were available in developed areas than in undeveloped ones both before (1994-1996) and after the bank reform (2001-2007). There are also few opportunities for firms to borrow across cities because local banks typically lend to local firms. Firms established in financially developed areas are always at a liquidity advantage compared with those firms that are located in underdeveloped areas. For example, firms in first-tier cities, e.g., Beijing and Shanghai, are more likely to be provided with loans both before and after the reform.

Thus, the bank loan supply before the reform (during the 1994-1996 period) is less likely 
to be responsive to firm demand after the reform. The geographical imbalance in financial development persists over time. Thus, the bank loan supply before the banking reform can be employed as an instrumental variable to proxy for the credit distribution.

We employ the number of bank branches and the number of banking employees from the "big four" state owned banks during the 1994-1996 period as an instrumental variables for the credit supply. Similar instrumental variables can be found in previous studies (e.g., Guiso, Sapienza, and Zingales, 2004, Minetti and Zhu, 2011, and Herrera and Minetti, 2007). By using these instrumental variables, we avoid the correlation between the credit supply during the 2000-2007 period and current exporting status during our sample period (also 2000-2007). The number of banks and the number of employees during the 1994-1996 period exert little effect on exporting behavior during the 2000-2007 period.

\subsubsection{Instrumental Variable Estimation}

Table 3 shows the regression results for the instrumental variable approach. In addition to the number of banks and employees during the 1994-1996 period, we use the number of employees multiplied by number of branches as a third instrumental variable.

Following the baseline regression, the standard deviation, percentile ratio, Theil index and Gini coefficient are calculated as credit distribution indices within each industry at the 4digit SIC level. We interact the industry dummy with the dispersion measurements as key dependent variables that indicate the different patterns of heavy and light industries. Industrylevel controls, e.g., average productivity, capital labor ratio, and average credit dependence, are included in this test. We also include year fixed effects and an industry-provincial dummy to control for time and region effects.

Columns 1-4 reports the results using export intensity as the dependent variable, and columns 5-8 show the results for export propensity. For all four measures of credit dispersion, i.e., standard deviation, percentile ratio, and Theil and Gini indices, the coefficients for credit dispersion are significant and negative, and the coefficients for the interaction terms are positive for both export intensity and exporter propensity.

The instrumental variable test supports our previous predictions that based on the industries' different natures, credit allocations play different roles in exporting. The F statistics suggest that the instrumental variables are immune from weak instrument problems, and the large $\mathrm{P}$ value for the Sagart J test indicates little concern about over-identification. The significant positive coefficients in the first stage and two diagnostic statistics support the validity of instrumental variables. 


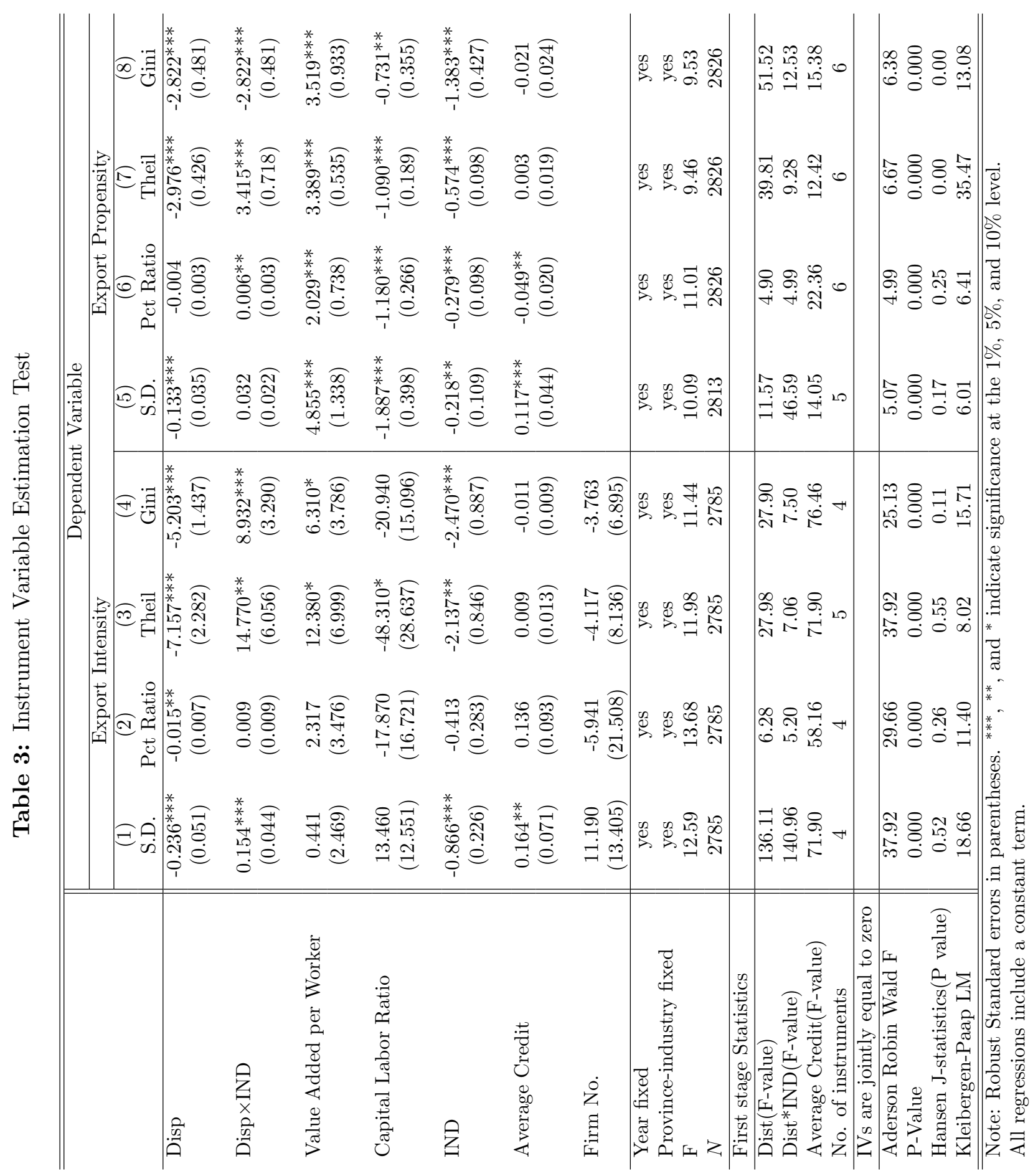




\section{Robustness}

\subsection{Subsamples by Ownership}

Firms with different ownership types face varying credit constraints and different tendencies to be export oriented. For example, SOEs, multinational enterprises (MNEs) and JVs may have advantages in obtaining bank loans from state-owned banks or liquidity support from foreign partners. Additionally, the latter two groups, i.e., MNEs and JVs, represent a larger proportion of China's export volume. To capture the effects of the credit distribution by ownership type, we conduct robustness tests for each ownership type in this section.

Table A.5 shows the results for SOEs, Table A.6 for domestic private firms, Table A.7 for JVs, and Table A.8 for MNEs. All four ownership subsamples include approximately 3300 industries covering the years from 2001 to 2007. In the left panel of the table, export intensity is used as the dependent variable, and the export propensity is the dependent variable in the right panel. Four credit dispersion measurements are employed for all subsamples: standard deviation, percentile ratio, and Theil and Gini indices.

In all tables, we list the results for firms by ownership type. The dispersion measurements have significant negative effects for all of four measurements. We have a positive significant coefficient for the interaction term when using all sets of measures. A similar pattern exists for the number of exporters in the right part of the table.

If we compare the coefficients for the four ownership types (e.g., for dispersion using the standard deviation), the magnitudes of the coefficients for MNEs (-1.219) and JVs (-1.151) are higher than those for SOEs (-0.906) and private domestic firms (-0.944). However, for heavy industries, this pattern is reversed. Because the positive effect of the dispersion interaction coefficients tend to be smaller, e.g., the interaction coefficient is 0.395 for JVs and 0.39 for MNEs. All of the above patterns among subsamples indicate that the negative effects of credit dispersion are magnified for JVs and MNEs, whereas the positive effects of credit dispersion for heavy industries tends to be larger among SOEs and private firms in China.

\subsection{Disaggregated Bank Loans}

In the previous tests, credit dispersion is computed based on bank loan data at the province level. There is concern that the province-level credit supply is a rough measure of the variance in terms of the credit constraints that firms in different cities face within the same province. Thus, we consider the city-level bank loan supply to investigate the baseline tests as a robustness check. 
The city-level specification is very similar with that in baseline specification, except that we add a province dummy to capture geographic agglomeration effects (specialization effects) at the province level for different industries. The dummy also alleviates the concern that industries that heavily depend on external financing tend to choose locations (provinces) with sufficient liquidity. The dummy is computed as the weighted share of provincial employment relative to the industries employment nationwide. We have 31 province dummies to represent 31 provinces in China. The set of province dummies varies for each industry in the sample.

Table A.9 reports the effects of credit dispersion on export intensity at the city level, and Table A.10 reports the effects on export propensity. Similar to the previous regression, we use four credit dispersion measurements: standard deviation, percentile ratio, and Gini and Theil indices. Columns 1, 3, 5 and 7 display the results without the set of provincial dummies, and columns 2, 4, 6, and 8 include the provincial dummies.

Dispersion Disp displays a significant, negative effect on export intensity when we use the standard deviation and percentile ratio, but this negative effect is not robust to the use of the Theil and Gini indices. The positive interaction effect for heavy industry, represented as Disp $\times I N D$, is not as robust to the use of city-level bank loan data. For the control variables, an increase in average credit supply stimulates exports. Productivity and the number of firms in an industry play negligible roles in exporting. For the industry dummy $I N D$, the negative coefficients show that light industries are still associated with a large fraction of exporters. The test of export propensity in Table A.10 reveals a similar pattern as observed for export intensity. For both tests, the province dummies can increase the performance of the specification, yielding higher $\mathrm{R}$ squared values, which indicate that geographic agglomeration effects at the industry level play an important role.

\section{Further Discussion}

In this section, we employ an alternative method of categorizing industries based on their foreign market penetration costs and then re-examine the hypothesized credit allocation effects on exports.

\subsection{Correlation of Coefficients and Export Penetration Costs}

We group all industries in the sample at the 2-digit level. After excluding those industry with fewer than 10 observations, we obtain 40 industries. We first regress exports (both export intensity and export propensity) on credit dispersion within the industry and then compare the coefficients across industries. We keep only the coefficients of Disp that are significant and 
exclude the insignificant ones.

If we look at the coefficients for industries such as petroleum and natural gas exploration, ferrous metal mining and textiles, credit dispersion shows a positive effect on exports. However, for industries such as food beverages and clothing, credit dispersion displays a negative effect on exports.

The correlations between the coefficients and export intensity/exporter ratio of the industry are around -0.44. The significantly negative sign shows that the effect of credit dispersion on exports decreases as the export intensity (exporter ratio) increases. Because export intensity/exporter ratio represent for the industry's penetration cost, this result indicates that greater credit dispersion decreases exports for industries with low penetration cost but encourages exports for industries with high penetration costs. Both the coefficients for individual industries and the correlation statistics between the two support the previous predictions about the credit distribution and export behavior.

\subsection{Ranking Industries by Export Penetration Cost}

According to the model, foreign market penetration costs are negatively correlated with both the fraction of exporters and the export intensity in an industry. ${ }^{22}$ In a further test, we use a ranking by fraction of exporters and export intensity to represent the exporting penetration costs for each industry (at the 4-digit SIC level). Then select the top 30th and the bottom 30th percentiles as the benchmarks. The former group (the top 30th percentile of export intensity/exporter fraction) represents industries with higher export barriers, whereas the bottom 30th percentile represents those with low export barriers. We check the effects of the credit distribution on the respective exports of these two groups.

In Table A.11, column 1 represents low penetration cost industries, and column 2 represents high penetration cost industries. The ranking of industries by penetration cost is based on the exporter ratio. In the left panel, the dependent variable is export intensity, and in the right panel, the dependent variable is number of exporters. If our prediction is valid, we expect a positive sigh on dispersion for the groups with high penetration costs (i.e., high $\phi$ ) and a negative sign on credit dispersion for those with small penetration costs (i.e., low $\phi$ ). The significant, negative signs in columns $1,3,5$, and 7 on the credit dispersion variables confirm our prediction that a more dispersed allocation discourages exports in industries with low foreign

\footnotetext{
${ }^{22}$ Assuming that firms differ in their productivity $x$, which follows a Pareto distribution. The number of exporters follows $\pi_{f}(x)=\frac{1}{\sigma} w^{*} L^{*}\left(\frac{\sigma}{\sigma-1} \frac{\tau w}{x P^{*}}\right)^{1-\sigma}-w^{*} C_{f} ; x^{\exp }=\left\{x \mid x>\left(\frac{\tau w}{w^{*}}\right)\left(\frac{C_{f}}{C_{d}^{*}}\right)^{\frac{1}{\sigma-1}} g\left(C_{d}^{*}\right)\right\}$. Thus, the ratio of exporter within an industry approximately indicates the foreign market penetration costs, as $\frac{N^{\exp }}{N}=$ $\left(\frac{\tau w}{w^{*}}\right)\left(\frac{C_{f}}{C_{d}^{*}}\right)^{\frac{1}{\sigma-1}}$.
} 
market penetration costs. In columns 4, 6 and 8, we see positive signs on the credit dispersion variables, which suggest that a dispersed allocation stimulates exports in industries with higher export barriers. However, there is a negative, insignificant coefficient on credit dispersion in column 2.

In Table A.12, the ranking of industries is based on export intensity. The negative signs on credit dispersion in columns 1, 3, 5 and 7 are very robust across all measurements. These results imply that the dispersion of credit supply may reduce the export intensity of low foreign market penetration cost industries. For high barriers to entry, in columns 2, 4, and 6, the positive signs are maintained across most measurements, but they not very stable for the number of exporters in column 8 .

\section{Conclusion}

In this paper, we propose that given an average credit supply, the distribution of that supply affects export behavior at the industry level. To provide evidence, we test our theory using Chinese firm-level data. This paper indicates that although the aggregate financing supply matters, the distribution of credit within an industry can either strengthen or weaken its effects. Depending on an industry's characteristics, the optimal allocation of credit supply varies for exports. By employing both ownership structure and bank loans as proxies for access to external financing, we find that for relatively low foreign market penetration costs, a more dispersed credit distribution decreases the industry's export intensity; conversely, for relatively high foreign market penetration costs, the dispersion of credit supply increases export intensity and the number of exporters in an industry.

Further research on external credit supplies and internal financing indices would benefit from an accurate firm-level credit constraint indicator. A well-rounded measure of the credit distribution as well as of the firm productivity distribution may allow more comprehensive and in-depth studies. Finally, we assume that the liquidity supply is independent of productivity. It would be interesting to relax this assumption and explore the conditions under which the two might be correlated especially in developing countries with the presence of credit misallocation. 


\section{References}

Allen, F., J. Qian, And M. Qian (2005): "Law, finance, and economic growth in China," Journal of Financial Economics, 77(1), 57 - 116.

Amiti, M., And D. E. Weinstein (2011): "Exports and Financial Shocks," The Quarterly Journal of Economics, 126(4), 1841-1877.

Aw, B. Y., AND A. R. Hwang (1995): "Productivity and the export market: A firm-level analysis," Journal of Development Economics, 47(2), 313-332.

Axtell, R., And R. Florida (2001): "Emergent Cities: A Microeconomic Explanation for Zipf's Law," Computing in Economics and Finance, 154.

BAI, C.-E., J. Lu, And Z. TAO (2006): "The Multitask Theory of State Enterprise Reform: Empirical Evidence from China," The American Economic Review, 96(2), pp. 353-357.

Bailey, W., W. Huang, And Z. YAng (2011): "Bank Loans with Chinese Characteristics: Some Evidence on Inside Debt in a State-Controlled Banking System," Journal of Financial and Quantitative Analysis, 46(06), 1795-1830.

Balasubramanian, N., And J. Sivadasan (2009): "Capital Resalability, Productivity Dispersion, and Market Structure," The Review of Economics and Statistics, 91(3), 547-557.

BECK, T. (2002): "Financial development and international trade: Is there a link?," Journal of International Economics, 57(1), 107-131.

Bernard, A. B., And J. B. Jensen (2004): "Entry, Expansion, and Intensity in the US Export Boom, 1987-1992," Review of International Economics, 12(4), 662-675.

BRANDT, L., AND H. Li (2003): "Bank discrimination in transition economies: ideology, information, or incentives?," Journal of Comparative Economics, 31(3), 387-413.

Chaney, T. (2013): "Liquidity Constrained Exporters," NBER Working Paper, (19170).

Chow, C. K. W., And M. K. Y. Fung (1998): "Ownership Structure, Lending Bias, and Liquidity Constraints: Evidence from Shanghai's Manufacturing Sector," Journal of Comparative Economics, 26(2), 301-316.

Cull, R., And L. C. Xu (2003): "Who gets credit? The behavior of bureaucrats and state banks in allocating credit to Chinese state-owned enterprises," Journal of Development Economics, 71(2), 533-559. 
di Giovanni, J., and A. A. Levchenko (2009): "Firm Entry, Trade, and Welfare in Zipf's World," Working Papers 591, Research Seminar in International Economics, University of Michigan.

Dixit, A. K. (1989): "Entry and Exit Decisions under Uncertainty," Journal of Political Economy, 97(3), 620-38.

Egger, P., And M. Kesina (2010): "Financial Constraints and Exports: Evidence from Chinese Firms," Working Paper.

FAN, H., E. L.-C. LAI, AND Y. A. Li (2015): "Credit constraints, quality, and export prices: Theory and evidence from China," Journal of Comparative Economics, 43(2), 390 - 416.

Feenstra, R., And H. L. KeE (2008): "Export variety and country productivity: Estimating the monopolistic competition model with endogenous productivity," Journal of International Economics, 74(2), 500-518.

Feenstra, R. C., Z. Li, And M. Yu (2014): "Exports and credit constraints under incomplete information: Theory and evidence from china," Review of Economics and Statistics.

Guariglia, A., X. Liu, and L. Song (2011): "Internal finance and growth: Microeconometric evidence on Chinese firms," Journal of Development Economics, 96(1), 79-94.

Guiso, L., P. Sapienza, And L. Zingales (2004): "Does Local Financial Development Matter?," The Quarterly Journal of Economics, 119(3), 929-969.

Helpman, E., M. J. Melitz, and S. R. Yeaple (2004): "Export Versus FDI with Heterogeneous Firms," American Economic Review, 94(1), 300-316.

Herrera, A. M., And R. Minetti (2007): "Informed finance and technological change: Evidence from credit relationships," Journal of Financial Economics, 83(1), 223 - 269.

Hricourt, J., and S. Poncet (2012): "Exchange Rate Volatility, Financial Constraints and Trade: Empirical Evidence from Chinese Firms," Working Papers 2012-35, CEPII research center.

Jarreau, J., And S. Poncet (2010): "Export Performance and Credit Constraints in China," Working Paper.

JU, J., AND S.-J. WEI (2011): "When is quality of financial system a source of comparative advantage?," Journal of International Economics, 84(2), 178-187. 
Kletzer, K., And P. BARdhan (1987): "Credit markets and patterns of international trade," Journal of Development Economics, 27(1-2), 57-70.

Li, H., L. Meng, Q. Wang, and L.-A. Zhou (2008): "Political connections, financing and firm performance: Evidence from Chinese private firms," Journal of Development Economics, 87(2), 283-299.

Manova, K. (2013): "Credit constraints, heterogeneous firms, and international trade," The Review of Economic Studies, 80(2), 711-744.

Manova, K., S.-J. Wei, and Z. Zhang (2014): "Firm Exports and Multinational Activity Under Credit Constraints," Review of Economics and Statistics.

Melitz, M. J. (2003): "The Impact of Trade on Intra-Industry Reallocations and Aggregate Industry Productivity," Econometrica, 71(6), 1695-1725.

Melitz, M. J., and G. I. P. Ottaviano (2008): "Market Size, Trade, and Productivity," Review of Economic Studies, 75(1), 295-316.

Minetti, R., And S. C. Zhu (2011): "Credit constraints and firm export: Microeconomic evidence from Italy," Journal of International Economics, 83(2), 109-125.

Poncet, S., W. Steingress, and H. Vandenbussche (2010): "Financial constraints in China: Firm-level evidence," China Economic Review, 21(3), 411-422.

Rajan, R. G., And L. Zingales (1998): "Financial Dependence and Growth," American Economic Review, 88(3), 559-86.

Roberts, M. J., And J. R. Tybout (1997): "The Decision to Export in Colombia: An Empirical Model of Entry with Sunk Costs," American Economic Review, 87(4), 545-64.

Song, Z., K. Storesletten, and F. Zilibotti (2011): "Growing Like China," American Economic Review, 101(1), 196-233. 


\section{Appendix A: Derivation of $X_{f}, X_{d}, R_{f}, R_{d}$}

$$
\begin{aligned}
& X_{f}=(1-\theta) \int_{\bar{x}(A)}^{\infty} \frac{x}{1-F(\bar{x}(A))} d F(x)+\theta \int_{\bar{x}(0)}^{\infty} \frac{x}{1-F(\bar{x}(0))} d F(x) \\
& =(1-\theta)\left(\frac{\bar{x}(A)}{\bar{x}_{d}}\right)^{\alpha} \int_{\bar{x}(A)}^{\infty} x d F\left(1-\left(\frac{b}{x}\right)^{\alpha}\right)+\theta\left(\frac{\bar{x}(0)}{\bar{x}_{d}}\right)^{\alpha} \int_{\bar{x}(0)}^{\infty} x d F\left(1-\left(\frac{b}{x}\right)^{\alpha}\right) \\
& =\frac{\alpha}{\alpha-1}\left[\left(\frac{\bar{x}(A)}{\bar{x}_{d}}\right)^{\alpha} \bar{x}_{d}^{\alpha}(1-\theta) \bar{x}(A)^{1-\alpha}+\theta \bar{x}(0)^{1-\alpha}\left(\frac{\bar{x}(0)}{\bar{x}_{d}}\right)^{\alpha} \bar{x}_{d}^{\alpha}\right] \\
& =\frac{\alpha}{\alpha-1}[(1-\theta) \bar{x}(A)+\theta \bar{x}(0)] \\
& \begin{aligned}
X_{d} & =(1-\theta) \int_{\bar{x}_{d}}^{\bar{x}(A)} \frac{x}{F(\bar{x}(A))} d F(x)+\theta \int_{\bar{x}_{d}}^{\bar{x}(0)} \frac{x}{F(\bar{x}(0))} d F(x) \\
& =(1-\theta) \frac{\bar{x}(A)^{\alpha}}{\bar{x}(A)^{\alpha}-\bar{x}_{d}^{\alpha}} \int_{\bar{x}_{d}}^{\bar{x}(A)} x d F\left(1-\left(\frac{b}{x}\right)^{\alpha}\right)+\theta \frac{\bar{x}(0)^{\alpha}}{\bar{x}(0)^{\alpha}-\bar{x}_{d}^{\alpha}} \int_{\bar{x}_{d}}^{\bar{x}(0)} x d F\left(1-\left(\frac{b}{x}\right)^{\alpha}\right) \\
& =\frac{\alpha}{\alpha-1}(1-\theta) \frac{\bar{x}(A)^{\alpha} \bar{x}_{d}-\bar{x}_{d}^{\alpha} \bar{x}(A)}{\bar{x}(A)^{\alpha}-\bar{x}_{d}^{\alpha}}+\frac{\alpha}{\alpha-1} \theta \frac{\bar{x}(0)^{\alpha} \bar{x}_{d}-\bar{x}_{d}^{\alpha} \bar{x}(0)}{\bar{x}(0)^{\alpha}-\bar{x}_{d}^{\alpha}}
\end{aligned} \\
& R_{f}=\kappa_{1}(1-\theta) \int_{\bar{x}(A)}^{\infty} \frac{x^{\sigma-1}}{1-F(\bar{x}(A))} d F(x)+\kappa_{1} \theta \int_{\bar{x}(0)}^{\infty} \frac{x^{\sigma-1}}{1-F(\bar{x}(0))} d F(x) \\
& =\kappa_{1}(1-\theta)\left(\frac{\bar{x}(A)}{\bar{x}_{d}}\right)^{\alpha} \int_{\bar{x}(A)}^{\infty} x^{\sigma-1} d F\left[1-\left(\frac{b^{\sigma-1}}{x^{\sigma-1}}\right)^{\frac{\alpha}{\sigma-1}}\right] \\
& +\kappa_{1} \theta\left(\frac{\bar{x}(0)}{\bar{x}_{d}}\right)^{\alpha} \int_{\bar{x}(0)}^{\infty} x^{\sigma-1} d F\left[1-\left(\frac{b^{\sigma-1}}{x^{\sigma-1}}\right)^{\frac{\alpha}{\sigma-1}}\right] \\
& =\kappa_{1}(1-\theta) \alpha \bar{x}_{d}^{\alpha}\left(\frac{\bar{x}(A)}{\bar{x}_{d}}\right)^{\alpha} \int_{\bar{x}(A)}^{\infty} x^{\sigma-\alpha-2} d x+\kappa_{1} \theta \alpha \bar{x}_{d}^{\alpha}\left(\frac{\bar{x}(0)}{x_{d}}\right)^{\alpha} \cdot \int_{\bar{x}(0)}^{\infty} x^{\sigma-\alpha-2} d x \\
& =\frac{\alpha \cdot \kappa_{1}}{1+\alpha-\sigma}\left[(1-\theta) \bar{x}(A)^{\sigma-1}+\theta \bar{x}(0)^{\sigma-1}\right]
\end{aligned}
$$




$$
\begin{aligned}
R_{d} & =\kappa_{2}(1-\theta) \frac{1}{F(\bar{x}(A))} \int_{\bar{x}_{d}}^{\bar{x}(A)} x^{\sigma-1} d F(x)+\kappa_{2} \theta \frac{1}{F(\bar{x}(0))} \int_{\bar{x}_{d}}^{\bar{x}(0)} x^{\sigma-1} d F(x) \\
& =\kappa_{2}(1-\theta) \int_{\bar{x}_{d}}^{\overline{x(A)}} x^{\sigma-1} d F\left[1-\left(\frac{b^{\sigma-1}}{x^{\sigma-1}}\right)^{\frac{\alpha}{\sigma-1}}\right]+\kappa_{2} \theta \int_{\bar{x}_{d}}^{\bar{x}(0)} x^{\sigma-1} d F\left[1-\left(\frac{b^{\sigma-1}}{x^{\sigma-1}}\right)^{\frac{\alpha}{\sigma-1}}\right] \\
& =\kappa_{2}(1-\theta) \alpha \bar{x}_{d}^{\alpha} \frac{\bar{x}(A)^{\alpha}}{\bar{x}(A)^{\alpha}-\bar{x}_{d}^{\alpha}} \int_{\bar{x}_{d}}^{\bar{x}(A)} x^{\sigma-\alpha-2} d x+\kappa_{2} \theta \alpha \bar{x}_{d}^{\alpha} \frac{\bar{x}(0)^{\alpha}}{\bar{x}(0)^{\alpha}-\bar{x}_{d}^{\alpha}} \int_{\bar{x}_{d}}^{\bar{x}(0)} x^{\sigma-\alpha-2} d x \\
& =\frac{\alpha \kappa_{2}}{1+\alpha-\sigma}(1-\theta) \frac{\bar{x}(A)^{\alpha} \bar{x}_{d}^{\sigma-1}-\bar{x}_{d}^{\alpha} \bar{x}(A)^{\sigma-1}}{\bar{x}(A)^{\alpha}-\bar{x}_{d}^{\alpha}}+\frac{\alpha \kappa_{2}}{1+\alpha-\sigma} \theta \frac{\bar{x}(0)^{\alpha} \bar{x}_{d}^{\sigma-1}-\bar{x}_{d}^{\alpha} \bar{x}(0)^{\sigma-1}}{\bar{x}(0)^{\alpha}-\bar{x}_{d}^{\alpha}}
\end{aligned}
$$




\section{Appendix B: More Tables}

Table A.1: Productivity and Bank Loan Supply at Firm Level

\begin{tabular}{r||cccc|cccc}
\hline \hline \multicolumn{1}{c||}{ dependent variable } & \multicolumn{7}{c}{ Firm's Productivity:Value added per worker } \\
\hline independent variable & $\begin{array}{c}\text { all credits } \\
\text { (province) }\end{array}$ & $\begin{array}{c}\text { long-term } \\
\text { (province) }\end{array}$ & $\begin{array}{c}\text { all credit } \\
\text { (city) }\end{array}$ & $\begin{array}{c}\text { long term } \\
\text { (city) }\end{array}$ & IE/TA & IE/TL & AP/TA & AP/TL \\
\hline & -0.0003 & -0.0047 & -0.0404 & -1.0858 & -3.5736 & 0.0401 & -10.8583 & -20.3428 \\
& $(0.0014)$ & $(0.0031)$ & $(1.5180)$ & $(3.6668)$ & $(3.7391)$ & $(0.1985)$ & $(12.9439)$ & $(13.3066)$ \\
\hline industry fixed effect & yes & yes & yes & yes & yes & yes & yes & yes \\
year fixed effect & yes & yes & yes & yes & yes & yes & yes & yes \\
ownership fixed effect & yes & yes & yes & yes & yes & yes & yes & yes \\
province fixed effect & no & no & no & no & yes & yes & yes & yes \\
\hline \hline
\end{tabular}

Notes: ${ }^{* *},{ }^{* *}$, and ${ }^{*}$ indicate significance at the $1 \%, 5 \%$, and $10 \%$ level. Standard errors in parentheses. All regressions include a constant term. IE/TA, IE/TL, AP/TL, and AP/TL are in log terms. IE, TA, TE, TL, AP denote interest expense, total assets, total equity, total liability, and account payable, respectively.

Table A.2: Distribution of Firms by Ownership Type

\begin{tabular}{c||cccc}
\hline \hline Year & SOE & DPE & MNE & JV \\
\hline 2001 & 27.64 & 54.90 & 6.14 & 11.32 \\
2002 & 21.42 & 60.04 & 7.22 & 11.32 \\
2003 & 17.55 & 63.47 & 7.96 & 11.02 \\
2004 & 12.95 & 67.39 & 8.95 & 10.71 \\
2005 & 9.25 & 70.07 & 10.84 & 9.84 \\
2006 & 6.88 & 72.38 & 11.23 & 9.52 \\
2007 & 5.42 & 74.42 & 11.35 & 8.81 \\
\hline \hline
\end{tabular}


Table A.3: Average Bank Loan to GDP Ratio by Province (2001-2007)

\begin{tabular}{|c|c|c|}
\hline Province & All Credit & Long-term Loan \\
\hline Hunan & 0.66 & 0.32 \\
\hline Tibet Autonomous Region & 0.66 & 0.34 \\
\hline Hebei & 0.70 & 0.27 \\
\hline Inner Mongolia Autonomous Region & 0.71 & 0.36 \\
\hline Henan & 0.72 & 0.26 \\
\hline Heilongjiang & 0.74 & 0.27 \\
\hline Shandong & 0.75 & 0.25 \\
\hline Jiangxi & 0.80 & 0.33 \\
\hline Guangxi Zhuang Autonomous Region & 0.80 & 0.43 \\
\hline Anhui & 0.84 & 0.32 \\
\hline Fujian & 0.86 & 0.36 \\
\hline Hubei & 0.87 & 0.41 \\
\hline Jiangsu & 0.90 & 0.31 \\
\hline Xinjiang Uygur Autonomous Region & 0.91 & 0.40 \\
\hline Sichuan & 1.00 & 0.46 \\
\hline Jilin & 1.01 & 0.40 \\
\hline Guangdong & 1.05 & 0.48 \\
\hline Gansu & 1.06 & 0.49 \\
\hline Liaoning & 1.06 & 0.42 \\
\hline Shanxi & 1.10 & 0.56 \\
\hline Hainan & 1.11 & 0.68 \\
\hline Shanxi & 1.11 & 0.46 \\
\hline Guizhou & 1.17 & 0.72 \\
\hline Yunnan & 1.20 & 0.59 \\
\hline Qinghai & 1.24 & 0.79 \\
\hline Chongqing City & 1.25 & 0.60 \\
\hline Tianjin Municipality & 1.33 & 0.58 \\
\hline Zhejiang & 1.35 & 0.44 \\
\hline Ningxia Hui Autonomous Region & 1.44 & 0.78 \\
\hline Shanghai Municipality & 1.61 & 0.78 \\
\hline Beijing Municipality & 2.29 & 1.27 \\
\hline
\end{tabular}

Source: Almanac of China's Finance and Banking 2007 
Table A.4: Dispersion of Credit Supply for 2-digit Industries

\begin{tabular}{l||cccc||c}
\hline \hline \multicolumn{1}{l||}{ Industry } & \multicolumn{4}{c}{ Bank Loans } & \multicolumn{1}{c}{ Liability } \\
\cline { 2 - 6 } Code & S.D. & Pct Ratio & Gini & Theil & S.D. \\
\hline 6 & 0.22 & 1.63 & 0.24 & 0.12 & 0.11 \\
7 & 0.30 & 1.83 & 0.33 & 0.20 & 0.28 \\
8 & 0.24 & 1.73 & 0.24 & 0.11 & 0.03 \\
9 & 0.20 & 2.01 & 0.28 & 0.20 & 0.02 \\
10 & 0.22 & 1.73 & 0.31 & 0.19 & 0.03 \\
11 & 0.15 & 1.51 & 0.34 & 0.20 & 0.01 \\
12 & 0.18 & 1.68 & 0.25 & 0.17 & 0.02 \\
13 & 0.28 & 1.79 & 0.32 & 0.18 & 0.02 \\
14 & 0.33 & 1.95 & 0.32 & 0.18 & 0.02 \\
15 & 0.30 & 1.88 & 0.34 & 0.20 & 0.03 \\
16 & 0.25 & 1.76 & 0.35 & 0.21 & 0.04 \\
17 & 0.27 & 1.83 & 0.22 & 0.11 & 0.02 \\
18 & 0.31 & 1.93 & 0.21 & 0.09 & 0.01 \\
19 & 0.28 & 1.76 & 0.26 & 0.13 & 0.01 \\
20 & 0.27 & 1.83 & 0.33 & 0.19 & 0.02 \\
21 & 0.32 & 1.92 & 0.26 & 0.13 & 0.01 \\
22 & 0.28 & 1.80 & 0.30 & 0.16 & 0.11 \\
23 & 0.44 & 2.49 & 0.30 & 0.17 & 0.01 \\
24 & 0.34 & 2.11 & 0.22 & 0.10 & 0.00 \\
25 & 0.32 & 1.88 & 0.29 & 0.16 & 0.13 \\
26 & 0.32 & 1.94 & 0.29 & 0.16 & 0.08 \\
27 & 0.36 & 2.00 & 0.31 & 0.17 & 0.03 \\
28 & 0.30 & 2.02 & 0.21 & 0.10 & 0.12 \\
29 & 0.31 & 1.91 & 0.27 & 0.14 & 0.03 \\
30 & 0.32 & 1.91 & 0.26 & 0.13 & 0.02 \\
31 & 0.33 & 2.00 & 0.29 & 0.15 & 0.02 \\
32 & 0.28 & 2.18 & 0.33 & 0.18 & 0.37 \\
33 & 0.30 & 2.03 & 0.32 & 0.19 & 0.10 \\
34 & 0.33 & 2.02 & 0.24 & 0.12 & 0.01 \\
35 & 0.35 & 2.02 & 0.23 & 0.11 & 0.02 \\
36 & 0.37 & 2.18 & 0.25 & 0.12 & 0.02 \\
37 & 0.36 & 2.22 & 0.27 & 0.14 & 0.07 \\
39 & 0.32 & 1.89 & 0.23 & 0.11 & 0.02 \\
40 & 0.40 & 2.24 & 0.23 & 0.11 & 0.09 \\
41 & 0.40 & 2.26 & 0.23 & 0.11 & 0.01 \\
42 & 0.30 & 1.89 & 0.25 & 0.13 & 0.01 \\
\hline \hline & & & & & \\
& & & &
\end{tabular}




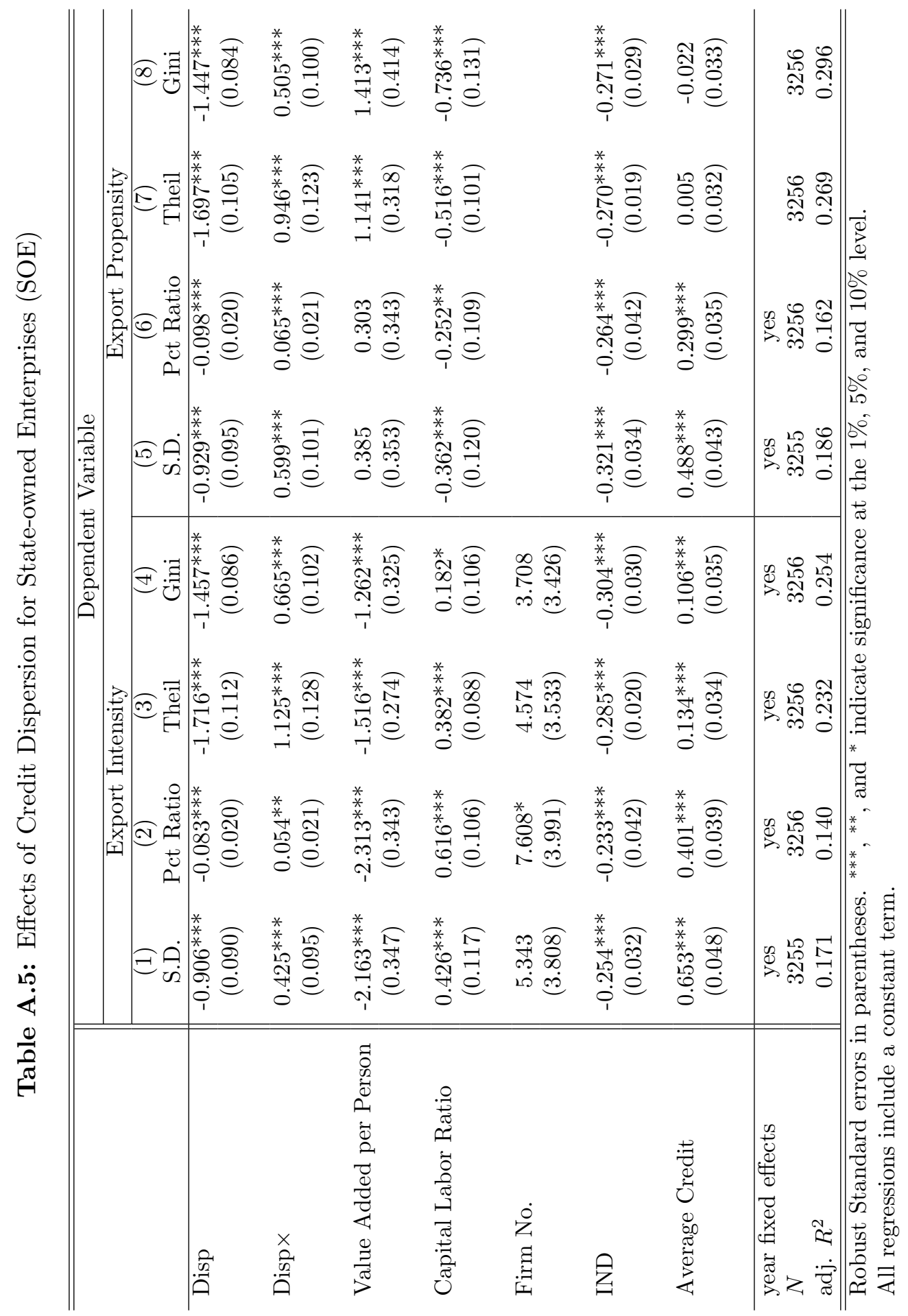




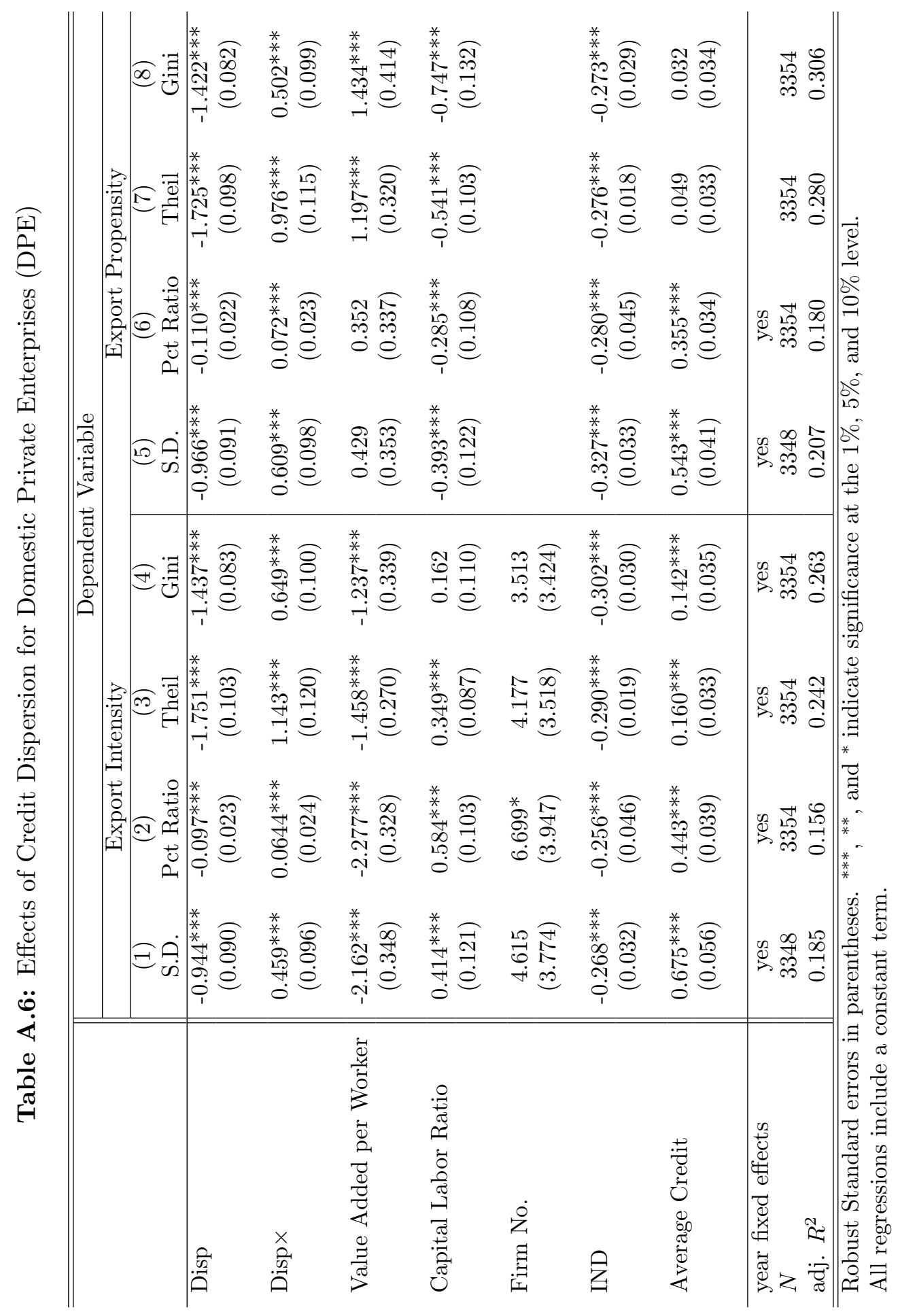




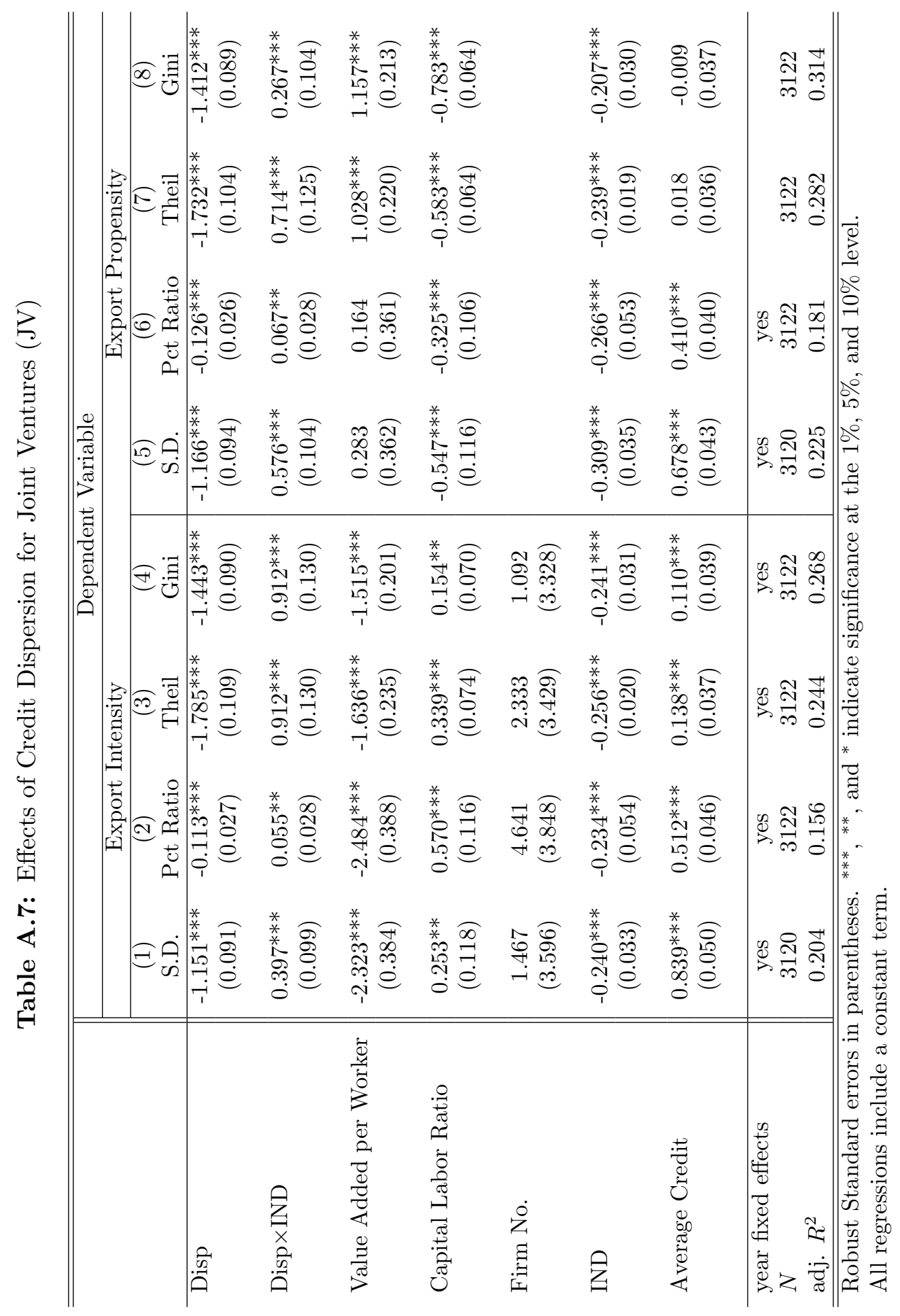




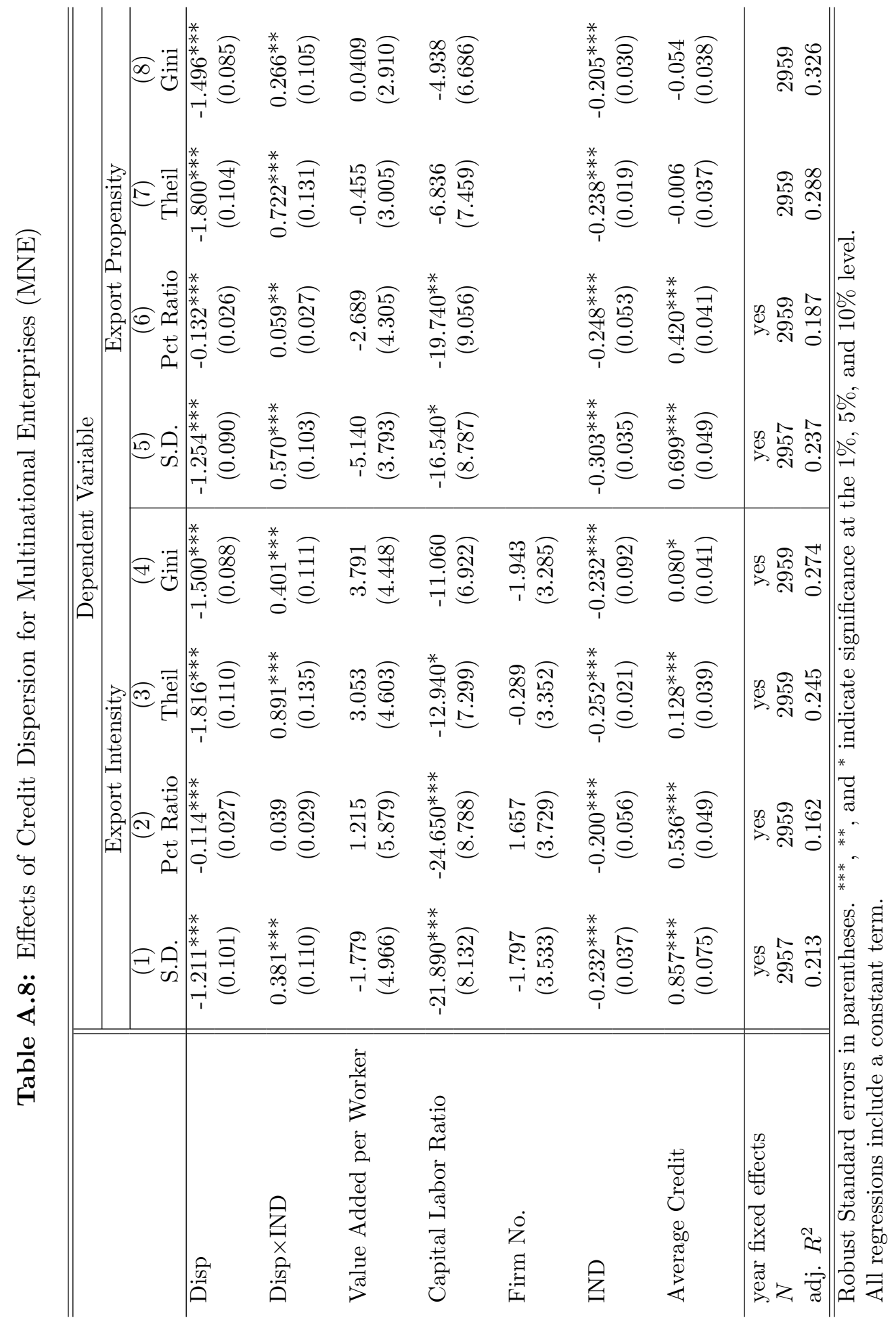




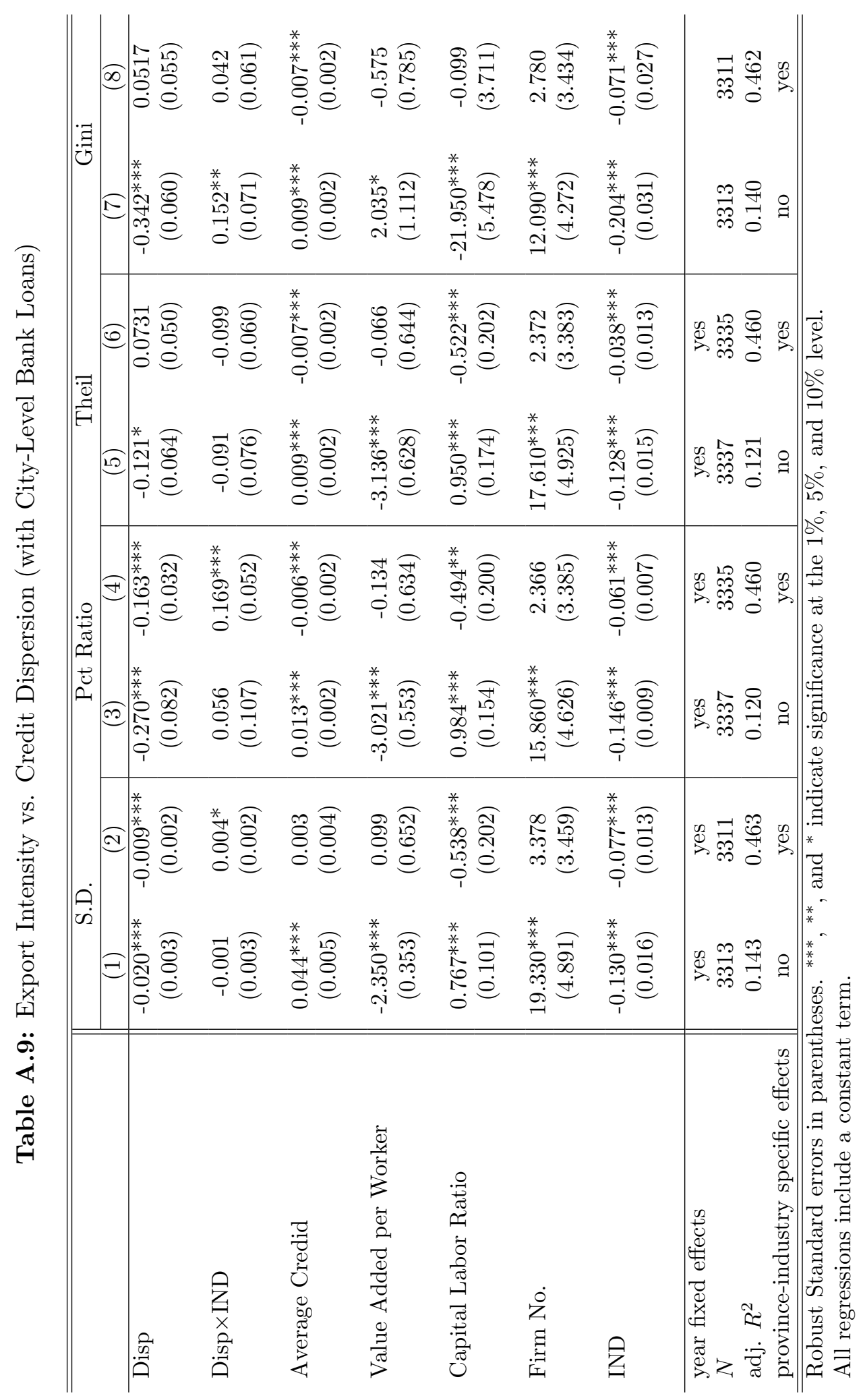




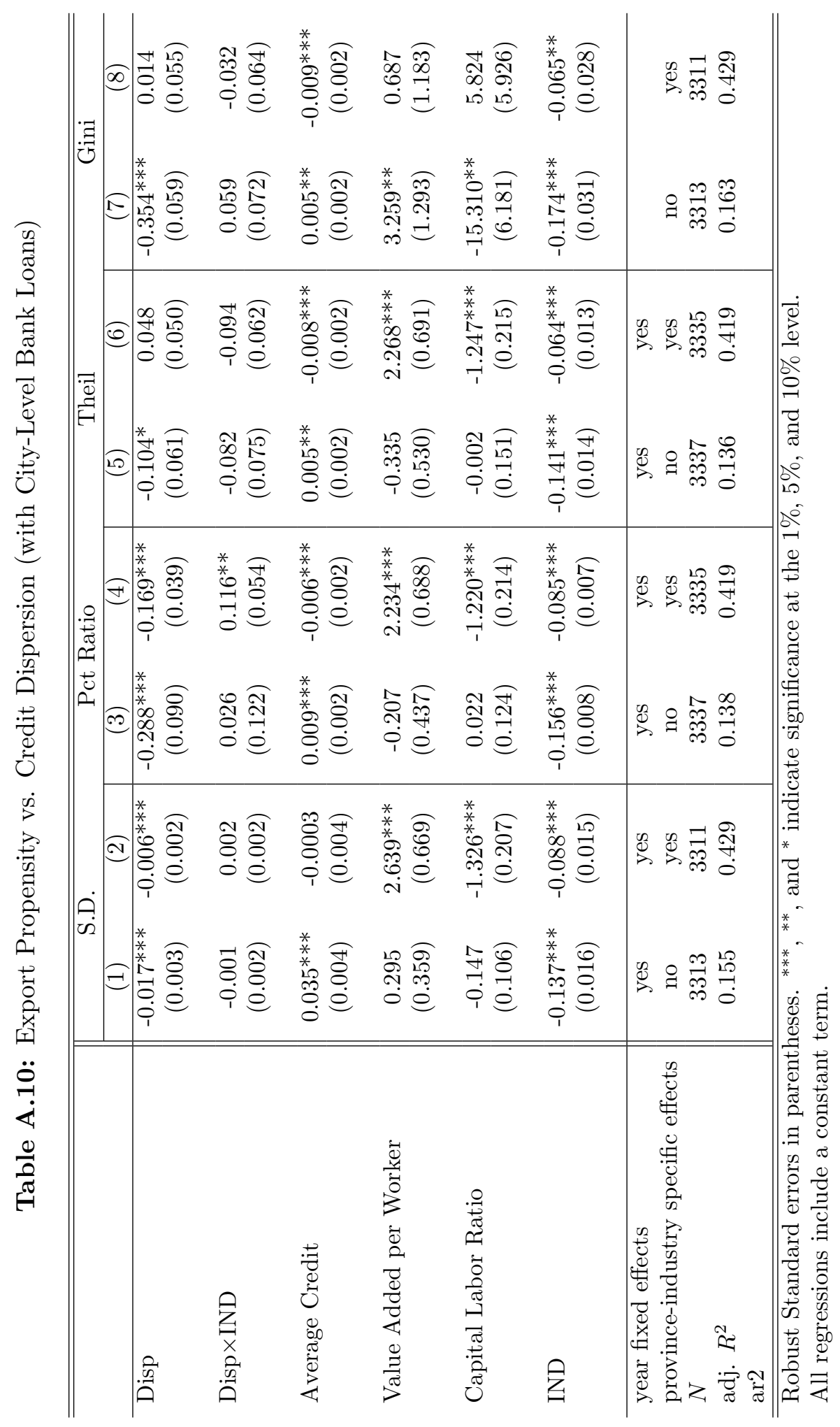


. 


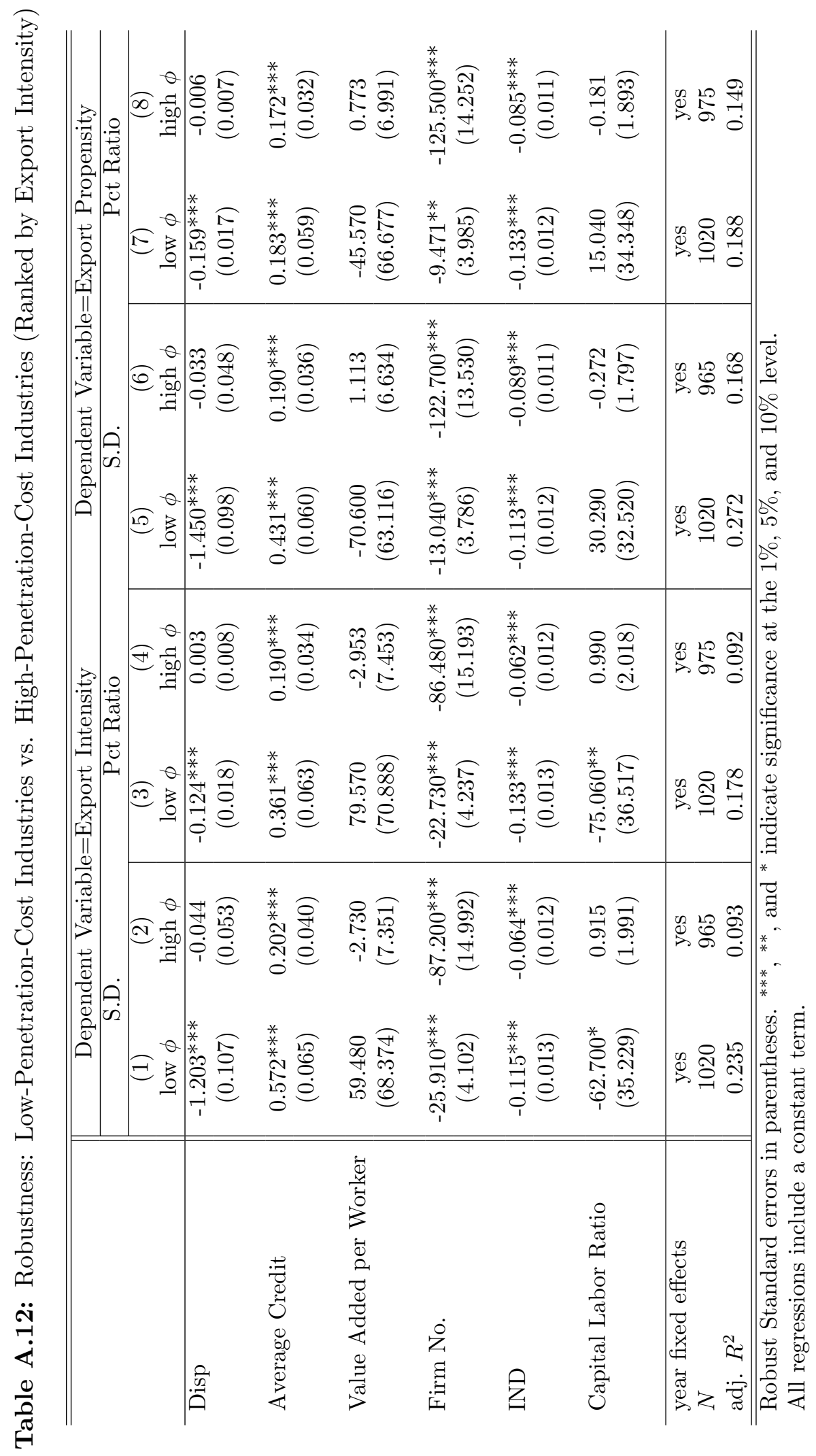




\section{Appendix C: The Calculation of Gini and Theil Index}

Gini index is widely used as inequality indicator. We divide the relative mean difference of the sample by two. If we ranking the credit supply in an non-decreasing order within an industry, that is $y i<y i+1$, we have

$$
\text { Gini }=\frac{1}{n-1}\left(n+1-2\left(\frac{\sum(n+1-i) y_{i}}{\sum y_{i}}\right)\right)
$$

where $\mathrm{n}$ is total firms in certain industry. The large Gini coefficient is, the more dispersion of credit supply, and zero stands for perfect equality of liquidity supply. In our test, for simplicity, we make use of relationship between Gini index and relative mean difference: Gini coefficient is half of the relative mean difference.

The Theil index is an statistic used to measure economic inequality or lack of diversity. We borrowed this widely used index to denote dispersion of liquidity supply as well. It is calculated by the following formula:

$$
\text { Theil }=\frac{1}{n} \sum\left(\frac{y_{i}}{\bar{y}} \ln \frac{y_{i}}{\bar{y}}\right)
$$

where $y_{i}$ is credit obtained by each firm and $\mathrm{n}$ is total number of firms within each industry. Average liquidity supply is denoted as $\bar{y}$. Large values means liquidity is allocated in a more dispersed way. 